\title{
Perfiles de la sexualidad: a propósito de las diferencias entre hombres y mujeres en Colombia*
}

\author{
Elias Sevilla Casas**
}

Se hace un ejercicio de descripción y de crítica sustantiva y metodológica del perfil de la conducta sexual de los colombianos como conjunto nacional, tal como aparece representada por dos variables de encuesta consideradas clave por los especialistas: la edad al inicio de la vida sexual interactiva (adulta), y el número de parejas sexuales habidas en el año anterior a la entrevista. La comparación sistemática de esta conducta se hace con la hallada por dos encuestas contemporáneas realizadas en Francia y Estados Unidos. Se encuentra en el caso colombiano un marcado contraste entre hombres y mujeres (dimorfismo) que hace aparecer a los primeros como los más precoces y de preferencia multipareja y a las segundas como las menos dentro de todo el conjunto comparado. Este hallazgo se toma como pretexto para hacer una serie de consideraciones sobre la pasada reticencia y actual creciente interés de la sociología sobre el tema de la sexualidad, el erotismo y el amor; sobre las dificultades metodológicas de este tipo de estudios por encuesta; y sobre posibles alternativas para despejar interrogantes que plantea para Colombia el dimorfismo descrito. Se concluye que los estudios por encuesta necesitan ser complementados por otras estrategias etnográficas, algunas indirectas, que permitan refinar hipótesis comunes como las de la dominación patriarcalista. Se alude a la necesaria complicidad, al menos por procuración, de las mujeres para que haya dominación masculina; se revisa la potencialidad de los estudios subculturales y subregionales planteados dentro de la estructuración histórica de desbalance sociorracial; y se hace mención de la aparentemente estrecha relación entre sexualidad y violencia. Se termina con la sugerencia de que en el caso de Colombia, conocido internacionalmente como país violento, podriamos acudir a la alternativa de estudiar con más cuidado "cómo se aman" los hombres y mujeres, adaptando para el caso un viejo adagio "dime cómo amas y te diré quien eres", arfin de descansar de la mucha tinta que ha corrido sobre la pregunta "cómo se matan".

Palabras clave: sociologia, encuestas, métodos, sexualidad, erotismo, amor, intimidad, hombres, mujeres, violencia, Colombia, Estados Unidos, Francia.

\section{Introducción}

Expectativas fallidas de una década

En octubre de 1994 se entregó al público un estudio nacional por encuesta sobre la sexualidad de los adultos estadunidenses realizado

* El autor agradece al Instituto de Seguros Sociales (Iss) de Colombia su autorización para utilizar la base de datos isscol./93. Igualmente agradece a los profesores y estudiantes de la Universidad del Valle y a los revisores anónimos que hicieron comentarios a una versión preliminar del estudio.

** Antropólogo PhD, profesor titular del Departamento de Ciencias Sociales, Facultad de Ciencias Sociales y Económicas, Universidad del Valle, Cali, Colombia. 
por un grupo de sociólogos de la Universidad de Chicago. Time Magazine International en su carátula del 19 de octubre habla de Surprising news from the most important survey since the Kinsey Report y resalta la seriedad e importancia del estudio sociológico. En las páginas interiores señala con sorpresa que la conducta sexual de los estadunidenses, tal como aparece descrita por la encuesta, es mucho más conservadora de lo que temían los políticos de derecha, entre ellos Jesse Helms, quienes habían hecho todo lo posible por impedir el estudio argumentando que los dineros federales que se pedían para realizarlo fomentarían indirectamente la relajación de las costumbres. Otros estudios nacionales; en particular el realizado en Inglaterra, llevan más o menos a las mismas conclusiones de frustración de los sensacionalistas. Como dice Lawrence Stone (1995), las encuestas, realizadas con todo cuidado y sin los sesgos obvios de los clásicos estudios de Kinsey y Hite, dan una idea de las sociedades dedicadas a asegurar prosaicos asuntos sexualmente convencionales, con una desafiante minoria desviada en un flanco, y una airada y acusadora minoria en el otro.

Pero más allá de la frustrada expectativa sensacionalista el estudio ha desencadenado una serie de debates de orden metodológico y sustantivo sobre la sexualidad como tema de investigación por la ciencia social que confirma la idea de que ha llegado el momento de superar las viejas reticencias sociológicas sobre el tema y encararlo con todos los recursos disponibles. Ante esta expectativa el historiador Stone lanza un oportuno caveat comentando que sólo los sociólogos, por lo que se deduce del estudio de Chicago, pueden hacer de este "agarrador tema" algo muy difícil de entender. Y, diríamos nosotros, algo fuertemente amenazado por la banalidad, el oportunismo, el sensacionalismo, o la bobería. En un comentario de prensa Richard Sennet (1995) no dudó en asignar este último calificativo al estudio de Chicago, haciendo referencia a la sociología y la seriedad de su producción, sobre la sexualidad y sobre otros dilemas de la sociedad contemporánea.

Porque la encuesta estadunidense no es un hecho aislado. Pertenece al conjunto bastante voluminoso de investigaciones sobre la sexualidad cuya ejecución ha sido propiciada por la angustia creciente que suscita el avance incontenible del sida. Hoy estos estudios, de toda envergadura, factura y calidad, realizados por científicos sociales de formación -y también por amateurs urgidos de resultados aplicables (o proyectos con "plata"), llenan las bases de datos bibliográficos. Todo mundo, de un momento a otro, resultó haciendo encuestas, 
particularmente encuestas $\mathrm{CAP},{ }^{1}$ y exploraciones etnográfícas "lanzadas”. La demanda de este tipo de estudios por parte de las instituciones médicas y de otros rectores de la vida pública, presionados por ellas, ha sido alta.

Como se sabe, dejando de lado su arrogancia tecnológica, la medicina se ha visto obligada a reconocer que la mejor $-\mathrm{y}$ hasta ahora única- "vacuna" contra el sida es el cambio de ciertas prácticas sexuales consideradas de riesgo por cuanto han aparecido en las investigaciones epidemiológicas como sistemáticamente asociadas con la infección por los virus del sida (wHo, 1988). Gran parte de los estudios realizados se emprendieron con la esperanza de ofrecer soluciones de efecto rápido y medible, ojalá mecánicas, tal como ocurrió hace algún tiempo con el uso de yodo en la sal para el control del bocio. Desde luego con el sida esos efectos rápidos no ocurrieron, pues el asunto de la sexualidad afecta resortes fundamentales y sumamente complejos de los sistemas psíquicos y sociales que son refractarios a las intervenciones simplistas que se tenían en mente. Tema agarrador pero en sí mismo complejo, Mr. Stone. Por eso, para no tomar sino un ejemplo, los cuatro frentes investigativos identificados por $\mathbf{M}$. $\mathrm{H}$. Merson (1993) como constitutivos del reto de la ciencia en los noventa en un número de Science enteramente dedicado al sida en su primera década, tocan todos de manera directa la conducta humana.

$\mathrm{Al}$ término de una década de esfuerzos no muy exitosos para contener la epidemia letal, se reconoce que la ciencia social ha aportado relativamente poco respecto a esta faceta de la vida social centrada en el goce de aquellos placeres que los paganos de la Grecia clásica denominaron aphrodisia, sobre los que, al decir de Gregory Bateson, hemos pasado siglos mintiéndonos a nosotros mismos (May, Anderson y Blower, 1989: 188). Por ello iniciamos la segunda década de la pandemia mortal todavía con ninguna o muy poca base de conocimiento científico social para hacer aportes significativos donde basar las intervenciones (Parker, Herdt y Carballo, 1991: 77). El reconocimien to de esta orfandad de modelos teóricos sólidos y resultados empíricos iluminadores sobre la sexualidad es bastante generalizado en sociolo-

${ }^{1}$ Los estudios CAP (conocimientos, actitudes, prácticas) fueron muy utilizados en la década pasada en los medios salubristas como un mecanismo directo y utilitarista de obtener "variables sociales" para sus planes de intervención. Su razonamiento simple y linear $\mathrm{C} \rightarrow \mathrm{A} \rightarrow \mathrm{P}$ ha sido mecánicamente refinado, unas veces agregándole módulos como "creencias" (CAPC), otras introduciendo ajustes al modelo básico de la conducta sexual. Un excelente manual CAP para sida y sexualidad es el de la ops (1993). 
gía, demografía y antropología aunque un poco menos en historia. ${ }^{2}$ El interés suscitado puede atribuirse a motivos que, con toda seguridad, desbordan ampliamente la preocupación por el sida, como se verá más adelante.

\section{La sociología y el estudio del pathos amoroso y erótico}

Ya en 1921 Simmel (1971: 235-236) había notado con cierto desencanto el desinterés de los pensadores sociales por el estudio riguroso de ese "gran tema vital" que es el amor y sus innegables relaciones con el alma, el destino y el ser. Atribuía este abandono a una decisión subjetiva que llevó a los pensadores a dedicarse al objeto de sus pensamientos (logos) pero no al de sus pasiones (pathos). No resulta extraña esta preferencia si -como anota Giddens (1992: 193) de pasada y con referencia a Marcuse, quien no se preocupa por las cuestiones del amor en un libro como Eros y civilización- los problemas de la modernidad, entendida como intento histórico de dar hegemonía a la razón, ha sido del dominio masculino. Habremos redondeado un argumento explicativo si a esto agregamos la circunstancia de que hay cierta correlación entre el predominio masculino en la sociología del pasado y el hecho, recalcado por Seidler (1987), de que el campo de la razón (logos) ha sido apropiado por los varones mientras el campo de la sinrazón y el sentimiento (pathos), al que se adscriben el amor, el erotismo y la sexualidad, ha sido dejado a las mujeres. ¿Qué dirán de todo esto las sociólogas que, parere, serán pronto mayoría en el gremio?

\section{Dificultades de orden metodológico en el estudio de la sexualidad}

Parece que uno de los motivos queijustificaría esta reticencia subjetiva de los sociólogos frente a la sexualidad tiene que ver, precisamente, con el fuerte componente subjetivo del fenómeno que se resiste a ser trata-

2 La psicología está en una situación diferente por su obvia asociación con la sexologia y el psicoanálisis, disciplinas que sí han hecho aportes notables en este campo. La antropología, a partir de los estudios clásicos de Malinowski, M. Mead y G. Róheim, no ha dejado de producir materiales etnográficos interesantes. Una breve revisión de este estado del arte se encuentra en Sevilla (1995) y en Bozon y Leridon (1993). Véase también Caplan (1987: 10-20). 
do con las metodologías "duras" desarrolladas en la disciplina para el tratamiento de los hechos sociales observables y medibles. Cicourel (1964) nos ayuda a formular con propiedad este argumento al recordarnos que el mismo Durkheim, exponente clásico al lado de Marx, del estudio de los hechos sociales y enemigo declarado de reducir la sociología a la sicología del individuo, se vio forzado a reconocer en su estudio pionero del suicidio que él no pretendía inferir conclusiones por medio del análisis de tasas de ocurrencias y otras variables "externas"

sustituir el exterior por el interior en sociología. Comenzamos por el exterior dado que sólo él nos es dado inmediatamente, pero sólo para alcanzar el interior. Sin duda el procedimiento es complicado...(Cicourel, 1964: 192).

La cuestión se agrava en los casos de la sexualidad, del erotismo y del amor -tomados aquí como un continuum de compleja arquitectura (Paz, 1993 y Sevilla, 1995)-, pues, a diferencia del suicidio, cuyo resultado obvio y directo, como en toda muerte, es lo único contable y lo demás es inferencia, la sexualidad humana se caracteriza por ser una vivencia interior (Bataille, 1988), que debe estudiarse por anamnesis. Sus resultados observables o contables, por ejemplo los hijos no deseados o ilegítimos, son ad latere pues nos sacan del campo objetual directamente concerniente a la sexualidad para ubicarnos en otro, por ejemplo el demográfico o legal. Salvo casos especiales de ejercicio de la sexualidad, como el de la prostitución, donde es posible generar alguna forma de registros, precisamente por darse en ambientes noprivados, la vida sexual cotidiana se le ofrece al sociólogo sólo por medio del recurso de la entrevista en cualquiera de sus formas.

Se debe, en efecto, acudir a la reconstrucción anamnésica para producir los datos que permitan cubrir los elementos críticos que se requieren en un estudio adecuado del fenómeno conducta sexual: las prácticas, los escenarios y las significaciones (Bajos y Spira, 1993). Tanto el horizonte externo o top half del fenómeno de que habla Cicourel como, y particularmente, el horizonte interno o bottom half deben ser reconstruidos a partir de lo que nos cuentan los actores.

A este:juego metodológico combinado han estado poco acostumbrados los sociólogos por la ausencia, dice Cicourel, de un adecuado modelo del actor, que sólo viene a perfeccionarse - a partir de las propuestas iluminadoras pero incompletas de Weber-con las corrientes fenomenológicas, en particular con las propuestas de Garfinkel y Schūtz, que distan mucho de haber sido asimiladas por el grueso de 
la sociología. Consciente o no de su ficción, el sociólogo construye un homúnculo o modelo artificial de actor con elementos pertenecientes a los dos horizontes, externo e interno. Este modelo le permite aproximarse a la realidad inalcanzable de la cotidianeidad mediante una doble tipificación, la originaria del actor que se desempeña en un campo social de interacciones y la que sobre ella construye el investigador al producir su modelo. Estos modelos típicos de actor en determinado campo, con sus motivaciones y razones, que son típicas también y por tanto artificiales, pueden ser sometidos a la prueba de los resultados de las intervenciones reales, por ejemplo de educación en prevención para el sida.

Pero el problema metodológico que afrontan los sociólogos, aun los que son amigos del homúnculo schutziano, se hace grave en el caso de la sexualidad. La gravedad nace del monopolio que tiene la anamnesis como fuente de datos porque -precisamente- la sexualidad ha sido sometida en la civilización occidental a un régimen muy particular en el orden discursivo. A partir de los estudios de Foucault (1976 y 1990) ha quedado claro que la sexualidad se convirtió en Occidente en un elaborado sistema de dominación que basó su dispositivo a partir del control en lo dicho sobre el uso de los placeres y aun sobre el deseo profundo e indeterminado que le da origen. De allí la importancia estratégica que Foucault (1990) asigna a la exagouresis pagana (ejercicio de verbalización de lo hecho). Asumida posteriormente en el régimen monacal del medievo para temas no sexuales la exagouresis abrió el camino más tarde a la confesión sacramental, la cual se especializó en hurgar en las intimidades de la acción sexual, realizada o fantaseada (los famosos "malos pensamientos" de la confesión católica) a tal punto que como examen de sí (hermenéutica del sujeto) se convirtió en el medio para detectar y tal vez ahogar en la misma fuente el deseo inconsciente. Vinieron luego la entrevista psicoanalítica y la historia clínica sexológica como formas secularizadas de la confesión.

Por tanto, dice Foucault, ante la imposibilidad de acudir a las visibilidades como fuente de información sobre el sexo, el discurso, debidamente condicionado por la cultura, se convirtió en el medio con que se construye el saber-poder, sin que de esta diagramación escape el saber científico. El anterior enunciado se completa con lo ya sabido en los medios sociológicos, y muy señalado en los medios antropológicos -que la conducta reportada, aun en los campos en que no hay reticencia cultural temática, se corresponde bastante mal con la con- 
ducta actuada-. Esta descen tración entre discurso y acción tiene aplicación aifortiori cuando se trata de la conducta sexual por las restricciones culturales arriba anotadas.

\section{Interés no coyuntural por el estudio de la intimidad amorosa}

La reticencia tradicional de los sociólogos y la dificultad metodológica que conlleva este tema vital, para volver a la expresión de Simmel, contrastan con la importancia capital que tienen para comprender cualquier sociedad. Al fin y al cabo, como dice Luhmann (1985) el amor y su medio simbiótico, la sexualidad, constituyen uno de los medios generalizados de comunicación en tre los hombres cuya semántica varía de paisaje cultural a paisaje cultural pero que persiste como un recurso necesario y central en todos ellos. El estudio de las relaciones personales y entre ellas de las íntimas y, especialmente, de las íntimas-eróticas/amorosas, resulta imprescindible para conocer realmente quiénes somos. Aduciendo que la sexualidad es, sobre todo, el medio por el cual la gente intenta ser consciente de sí misma, es decir de constituir su identidad como sujetos, Richard Sennet (Sennet y Foucault, 1981: 47) propone parafrasear el viejo adagio: $d i$ me cómo amas y te diré quién eres.

Esta importancia se acentúa respecto de la sociedad contemporánea por cuanto, según algunos observadores perceptivos, los trastornos de la modernidad tardía, diagnosticados por algunos como la era del vacío y del individualismo narcicista (Lipoweski, 1993) o como el rapport solitaire au monde (Augé, 1993), tienen mucho que ver con la subversión, desde abajo, de la infraestructura personal y la transformación de las reglas de juego de las transacciones intimas (Giddens, 1992). Los arreglos vigentes hasta hace poco, que las feministas denominan estructura machista y patriarcal o investigadores como Seidler (1987) distribución de preeminencia por géneros entre los dominios de la razón y la no-razón, están siendo subvertidos radicalmente. Aparece entonces un nuevo campo analítico de importancia estratégica para quien desee hacer una juiciosa crítica de la sociedad en que vivimos. Giddens lo denomina el campo de la life politics. El campo de la política había sido concebido como de dominio público (y masculino). Ahora la life politics, que se despliega preferentemente en los espacios privados e íntimos, adquiere relevancia y por primera vez resulta imprescindible ampliar el rango de mira del estudio sociológico hasta estos espacios. 
Por tanto, después de tratar de entender la reticencia que ha tenido en el pasado la sociología para trabajar el tema, notamos que la preocupación coyuntural por el auge del sida coincide con un interés más de fondo por dar tratamiento cuidadoso al difícil tema de la intimidad placentera y amorosa. En respuesta a tal conveniencia hemos querido aprovechar la ocasión de tres estudios nacionales por encuesta para compartir con el lector algunas reflexiones de orden metodológico y sustantivo que, además de bosquejarnos desde un ángulo inusual el perfil del país Colombia, por tantos conocido como nación de seres violentos, dejan planteadas preguntas e hipótesis sobre el dichoso y sufrido tema del amoury el erotismo.

\section{La oportunidad de tres encuestas y dos variables clave}

En el ejercicio cotidiano de consultoría en una institución de salud llegó a nuestro Grupo de Trabajo sobre Sexualidad y Salud ${ }^{3}$ una base de datos procedente de una encuesta nacional colombiana de respetables antecedentes técnico-científicos y amplia cobertura. Pareció interesante intentar un bosquejo comparativo entre el perfil estadunidense producido por la encuesta de la Universidad de Chicago y el caso colombiano. Como también se tenía a la mano la publicación de los resultados de otra respetable encuesta nacional realizada en Francia, la idea quedó redondeada para una comparación tripartita. De este modo se dio una oportunidad de incursionar críticamente en un frente interesante y compartir en este artículo los resultados, que se presentan en un doble plano: en el metodológico, pues discutiremos la pertinencia y alcance de estudios nacionales por encuesta de algo tan intimo y personal como la vida erótica, y en el sustantivo, pues trataremos de aprovechar unos datos que dentro de sus obvias limitaciones son mejores que las meras suposiciones para avanzar en el conocimiento de "cómo se aman los colombianos".

Se busca, entonces, en el presente texto aprovechar en esta ocasión tres estudios de encuesta producidos bajo la preocupación coyuntural del control del sida, para cumplir con tres objetivos que se ubican expresamente "más acá" de la aplicación salubrista, en los dominios de la investigación social básica: 1) bosquejar un perfil nacio-

\footnotetext{
${ }^{3}$ Grupo de Trabajo en Salud y Sexualidad, Facultad de Ciencias Sociales y Económicas, Universidad del Valle, Cali, Colombia.
} 
nal, diferenciado para hombres y mujeres, de la conducta de los colombianos, tal como aparece en dos variables que se consideran clave entre los especialistas; 2) comparar este perfil con el reportado para Estados Unidos y para Francia; y 3) hacer algunas consideraciones que definan los alcances de este tipo de comparaciones nacionales basadas en encuesta, resalten ciertas anomalías encontradas en el perfil erótico colombiano y ayuden a formular preguntas fértiles y viables para las investigaciones en curso.

\section{Aspectos metodológicos de las encuestas}

La ficha técnica de las tres encuestas es la siguiente:

i) El estudio Analyse des comportements sexuels en France (AcsF) fue realizado entre 1991 y 1992 por un consorcio de instituciones pertenecientes a las Universidades de la Isla de Francia con un equipo de sociólogos, epidemiólogos, demógrafos, economistas, psicólogos, estadísticos y matemáticos bajo la dirección del epidemiólogo Alfred Spira y de la sociodemógrafa Nathalie Bajos. Los resultados fueron presentados en un número especial de Population (Bozon y Leridon, 1993). La muestra nacional francesa estuvo constituida por una selección aleatoria de 20055 hombres y mujeres abonados telefónicos de France-Telecom con edades entre 18 y 69 años. La información se recogió mediante un cuestionario corto aplicado telefónicamente a todos los seleccionados y otro largo, aplicado a un grupo de 4820 personas de la muestra que cumplían con algunos requisitos adicionales. Para el presente trabajo no se tuvo acceso a la versión completa del cuestionario utilizado sino a una síntesis descriptiva.

ii) El estudio National Health and Social Life Survey (NHSIs) ${ }^{4}$ fue realizado en 1992 por un equipo de tres sociólogos y un economista de la Universidad de Chicago; los resultados fueron publicados en un libro especializado (Laumann et al., 1994) y en otro con destino al gran público. La muestra aleatoria nacional estadunidense estuvo constituida por 3432 hombres y mujeres entre 18 y 60 años, de los cuales 273 fue-

4 Debió denominarse así para minimizar el impacto negativo que en la opinión pública y de los políticos conservadores de Estados Unidos hubiera tenido un nombre más explícito, ya que la propuesta inicial se hizo para ser financiada con fondos federales, que finalmente nunca llegaron. 
ron una cuota ampliada correspondiente a negros e hispanos. Esta muestra se tomó del Marco Muestral Nacional de Residencias 1980 del National Opinion Research Center, NoRc, cuya estructura es probabilística, de cluster multietápica. La información se recogió con un detallado cuestionario único aplicado mediante entrevista con la persona que resultó seleccionada en la muestra de residencias.

iii) La información que aquí se utiliza para Colombia (Isscol/93) procede de un estudio cap que sobre enfermedades cardiovasculares, cáncer, enfermedades de transmisión y sida patrocinó el Instituto de Seguros Sociales (Iss) de Colombia y ejecutó en 1993 en asociación con el Instituto Nacional de Cancerología y la ong Profamilia. El equipo que diseñó y ejecutó la encuesta estuvo constituido por médicos, demógrafos, epidemiólogos y estadísticos. Los hombres y mujeres adultos entre 18 y 69 años -hubo también una encuesta para adolescentes- estuvieron representados por una muestra probabilística nacional de hogares, tipo cluster multietápico, que produjo finalmente 5026 cuestionarios útiles de hombres y 6949 de mujeres, correspondientes al territorio nacional, con exclusión de las áreas orien tales amazónico-orinoquenses e insulares. Esta muestra se obtuvo utilizando la Muestra Maestra Nacional de Profamilia, entidad que cuenta con una amplia trayectoria en encuestas relacionadas con la salud, la sexualidad y la reproducción, obtenida en su exitoso trabajo sobre planificación familiar que lleva ya dos décadas. La asesoría para el muestreo estuvo a cargo de uno de los mejores especialistas con que cuenta el país.

El cuestionario se componía de varios módulos correspondientes a los temas de estudio: identificación; características individuales; riesgos cardiovasculares y tabaquismo; relaciones sexuales y ETs-sida; citología vaginal; incapacidades y accidentes; relaciones de pareja. Fue administrado en entrevistas individuales por encuestadoras debidamente capacitadas y supervisadas por Profamilia (Iss Colombia, 1994, I). Los resultados preliminares de la encuesta en forma de frecuencias simples y cruzadas fueron publicados por el iss en cinco volúmenes. Los datos utilizados para el presente estudio proceden directamente de la base de datos entregada por el iss a la Universidad del Valle para que realizara un análisis global de tipo antropológico y epidemiológico (Sevilla et al, 1995) y su uso fue gentilmente autorizado por el iss.

De estas fuentes se toman para el presente estudio las variables de "edad a la primera relación sexual", y "número de parejas diferentes" habidas en el último año, como indicadores gruesos de la conducta 
sexual. Se trabaja con la presunción de que, a pesar de todo lo que se ha dicho sobre la dificultad de captar conductas actuadas por medio de conductas reportadas en encuesta, se cumple el criterio básico de veracidad prima facie en las respuestas y de comparabilidad entre las encuestas. Esta presunción será sometida a cuestionamiento en la sección de discusión, pero por ahora da soporte a la presentación misma de los resultados.

\section{Resultados comparativos}

\section{Ausencia previa de experiencia sexual interactiva}

Antes de entrar al estudio de las variables centrales del presente estudio es conveniente detenernos en los datos disponibles sobre el reporte de ausencia de relaciones sexuales habidas en el curso de la vida. Ante la pregunta de si se habían tenido relaciones sexuales en el curso de la vida la respuesta se comporta de este modo: en Colombia $97 \%$ de los hombres colombianos respondió afirmativamente y $88 \%$ de las mujeres; en Estados Unidos lo hicieron afirmativamente 95.8\% de los hombres y $97.3 \%$ de las mujeres. Ya aquí se insinúa un mayor dimorfismo hombre-mujer para Colombia que para Estados Unidos, de tal modo que los grupos comparados se ubican así, en el continuum de mayor a menor experimentación sexual: H-Col, H-EU, M-EU, M-Col. Este patrón que ubica a los hombres y mujeres de Colombia en los extremos del continuum comparativo se repetirá sistemáticamente en los hallazgos descritos en seguida. No hubo datos para hacer la comparación con Francia.

\section{La edad de la primera relación sexual}

La pregunta de la encuesta colombiana fue "¿A qué edad tuvo usted su primera relación sexual?", que dejó sin precisar el sentido de la frase y el contenido práctico ${ }^{5}$ de "relación sexual". La encuesta estaduni-

\footnotetext{
${ }^{5}$ En términos de contactos corporales que excitan sexualmente. En la formulación operativa francesa la conducta sexual se categoriza en estos tres componentes: prácticas, escenarios y significaciones (Bajos y Spira, 1993: 1214). Las prácticas coinciden en la terminología freudiana de los Tres ensayos con los fines sexuales.
} 
dense preguntó sobre la primera persona con quien el entrevistado "tuvo sexo" ( had sex), y sus circunstancias, incluyendo los datos sobre la edad y otras características del encuentro. Ya se había explicado en el curso de la encuesta que "sexo" o "actividad sexual" significaba cualquier actividad con otra persona que involucra contacto genital y excitación sexual, esto es, feeling really turned on, aun en el caso de que no ocurriera coito $u$ orgasmo. Durante el análisis de la variable los autores hablan de sexual intercourse haciendo mayor hincapié en el partnered sex y particularmente en el vaginal intercourse, que de hecho es reportado por $95 \%$ de los hombres y $96 \%$ de las mujeres entrevistados. La encuesta francesa habla del premier rapport sexuel, no lo reduce a la relación coital, y lo considera la entrada a la sexualidad adulta. Se puede pensar que el punto de convergencia implícito de las tres formas de preguntar y de entender la pregunta es la calidad interactiva genital de la experiencia sexual. ${ }^{6}$

Las estadísticas descriptivas de la variable "edad a la primera relación sexual" de la subpoblación con experiencia sexual de Colombia son, para los hombres: media 15.2, desviación estándar 4.4, mediana 15, y moda 15. De ellos, $4.4 \%$ reportó relaciones sexuales en edades de 11 o menos años; de 12 o menos $11.2 \%$ y de 13 o menos $18.4 \%$. A los 30 años $99.6 \%$ ya había tenido relaciones sexuales. En las mujeres la media de edad a la primera relación sexual es 16.5 , la desviación estándar 7.5 , la mediana 18 y la moda 18 ; reportó relaciones sexuales a edades de 11 años o menos, $0.6 \%$; de 12 o menos $1.4 \%$, y de 13 o menos $3.2 \%$. A los $30,98.7 \%$ ya había tenido relaciones sexuales.

Los autores de la encuesta francesa atribuyen un valor especial al premier rapport sexuel como predictor de estilos de conducta sexual posterior. No hacen lo mismo los autores de la encuesta estadunidense respecto al first sexual intercourse, pero sí son claros en afirmar que la información disponible sobre contactos de preadolescentes con adultos o adolescentes (touched sexually) permite concluir que esos contactos tienen efectos negativos sobre la vida sexual adulta poste-

${ }^{6}$ La distinción entre "primera relación sexual" (first sexual intercourse, premier rapport sexuel) como entrada a la vida sexual de tipo adulto, y experiencias coactivas y abusivas que sufren los niños por parte de adultos o adolescentes, o experiencias ingenuas puramente infantiles, es muy tenue, pero es aceptada sin mayor discusión en el lenguaje común y en el especializado de estas encuestas. El estudio de Estados Unidos dedica un capítulo a estas otras experiencias y las distingue del first sexual intercourse. En las otras dos encuestas no se hace referencia a estas otras experiencias. Volveremos sobre estas experiencias previas al discutir los hallazgos (véase infra pp. 290-292). 
rior. Este importante punto será discutido al final, en la sección correspondiente.

Las gráficas 1 y 2 , generadas a partir del cuadro 1 , permiten comparar en detalle el comportamiento de las medias de edad a la primera relación sexual para diferentes cohortes de nacimiento de hombres y mujeres de Colombia y Francia por un lado y Colombia y Estados Unidos por el otro. En el eje de las $X$ se presentan las cohortes de nacimiento (en décadas) ajustando los datos de Colombia a los datos publicados para Francia y Estados Unidos. Igualmente se presenta entre paréntesis la década histórica aproximada en que estas cohortes estaban teniendo esa primera relación. Ejemplo: agregando a la cohorte nacida en el periodo 1937-1946 los años transcurridos desde su nacimiento hasta la edad promedio en que declaran haber tenido su primera relación sexual, nos ubicamos en la década que va de mitad de los cincuenta a mitad de los sesenta. Este contexto coyuntural de corto plazo en que se da la iniciación interactúa sin duda con el condicionamiento cultural más de largo plazo representado por su experiencia socializadora a partir del nacimiento.

En conjunto, las gráficas 1 y 2 y los datos adicionales presentados, entre ellos los del cuadro 1, ameritan los siguientes comentarios descriptivos:

a) En cuanto a experiencia previa de relaciones sexuales, se observa en Colombia un marcado dimorfismo hombre-mujer en cuanto a la proporción de adultos con tal experiencia. Comparados con Estados Unidos, los hombres colombianos tienen una proporción ligeramente más alta y en las mujeres se da un fenómeno muy peculiar que acentúa el dimorfismo colombiano: las mujeres estadunidenses con experiencia previa tienen proporciones más altas que sus hombres y en cambio las mujeres colombianas están 9 puntos porcentuales por debajo de sus hombres.

b) La anterior tendencia se acentúa al observar las medias de edad en que se reporta la primera relación sexual (gráficas 1 y 2): las cohortes femeninas colombianas reportan edades promedio sistemática y notablemente mayores que las cohortes masculinas colombianas y en general que todas las cohortes femeninas comparadas (exceptuando un cruce de curvas con las mujeres francesas que se da para las cohortes 67-71). Los hombres colombianos presentan un comportamiento exactamente opuesto: se ubican en el nivel promedio más bajo de edad a la iniciación sexual comparado con todas las cohortes masculinas de las gráficas, con la notable excepción de los varones negros de Estados Unidos. 


\section{CUADRO 1}

Promedio de edad en que hombres y mujeres dicen haber tenido la primera relación sexual por cohortes de nacimiento en Colombia y Francia, y Colombia y Estados Unidos (y por categorización sociorracial para Estados Unidos)

\begin{tabular}{|c|c|c|c|c|c|c|}
\hline & \multicolumn{6}{|c|}{ Comparación Colombia-Francia } \\
\hline & \multicolumn{2}{|l|}{$\begin{array}{l}\text { Hombres } \\
\text { Francia }\end{array}$} & $\begin{array}{l}\text { Mujeres } \\
\text { Francia }\end{array}$ & \multicolumn{2}{|c|}{$\begin{array}{l}\text { Hombres } \\
\text { Colombia }\end{array}$} & $\begin{array}{c}\text { Mujeres } \\
\text { Colombia }\end{array}$ \\
\hline Nacidos en 1992-1936 & 18.4 & & 21.3 & \multicolumn{2}{|c|}{16.9} & 19.4 \\
\hline Nacidos en 1937-1946 & 18.5 & & 20.3 & \multicolumn{2}{|c|}{15.9} & 19.4 \\
\hline Nacidos en 1947-1956 & 17.8 & & 18.8 & \multicolumn{2}{|c|}{15.9} & 19.3 \\
\hline Nacidos en 1957-1966 & 17.3 & & 18.1 & \multicolumn{2}{|c|}{15.6} & 19.0 \\
\hline Nacidos en 1967-1971 & 17.5 & & 18.2 & \multicolumn{2}{|c|}{15.3} & 17.7 \\
\hline \multirow[t]{3}{*}{ Nacidos en 1972-1973 } & 17.2 & & 18.1 & & .0 & 16.1 \\
\hline & \multicolumn{6}{|c|}{ Comparación Colombia-Estados Unidos } \\
\hline & $\begin{array}{c}\text { Blancos } \\
E U\end{array}$ & $\begin{array}{c}\text { Blancas } \\
E U\end{array}$ & $\begin{array}{c}\text { Negros } \\
E U\end{array}$ & $\begin{array}{c}\text { Negras } \\
E U\end{array}$ & $\begin{array}{l}\text { Hombres } \\
\text { Colombia }\end{array}$ & $\begin{array}{c}\text { Mujeres } \\
\text { Colombia }\end{array}$ \\
\hline Nacidos en 1933-1942 & 18.0 & 18.8 & - & 17.2 & 16.3 & 19.4 \\
\hline Nacidos en $1943-1952$ & 17.7 & 18.0 & 15.6 & 17.7 & 15.9 & 19.6 \\
\hline Nacidos en 1953-1962 & 17.1 & 18.0 & 15.5 & 17.7 & 15.7 & 19.1 \\
\hline Nacidos en 1963-1967 & 17.5 & 17.9 & 15.3 & 17.0 & 15.7 & 18.8 \\
\hline
\end{tabular}

Fuentes: Francia, Bozon y Leridon, 1993: 1320; Estados Unidos calculado de figura 9.1 en Laumann et al., 1994: 325; Colombia: Isscol/93.

GRÁFICA 1

Promedio de edad de hombres y mujeres de Francia y Colombia en su primera relacion sexual, por cohortes de nacimiento

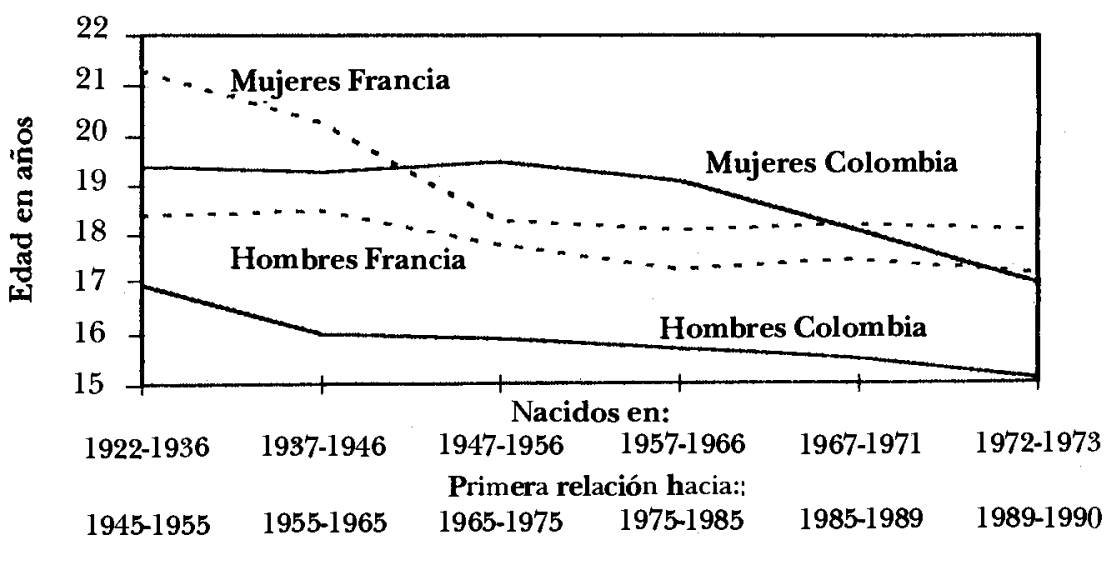

Fuente: Colombia, Isscol/93; Francia, Bozon y Leridon, 1993. 
GRÁFICA 2

Promedio de edad de hombres y mujeres de Colombia y Estados Unidos por cohorte de nacimiento, y en Estados Unidos por race

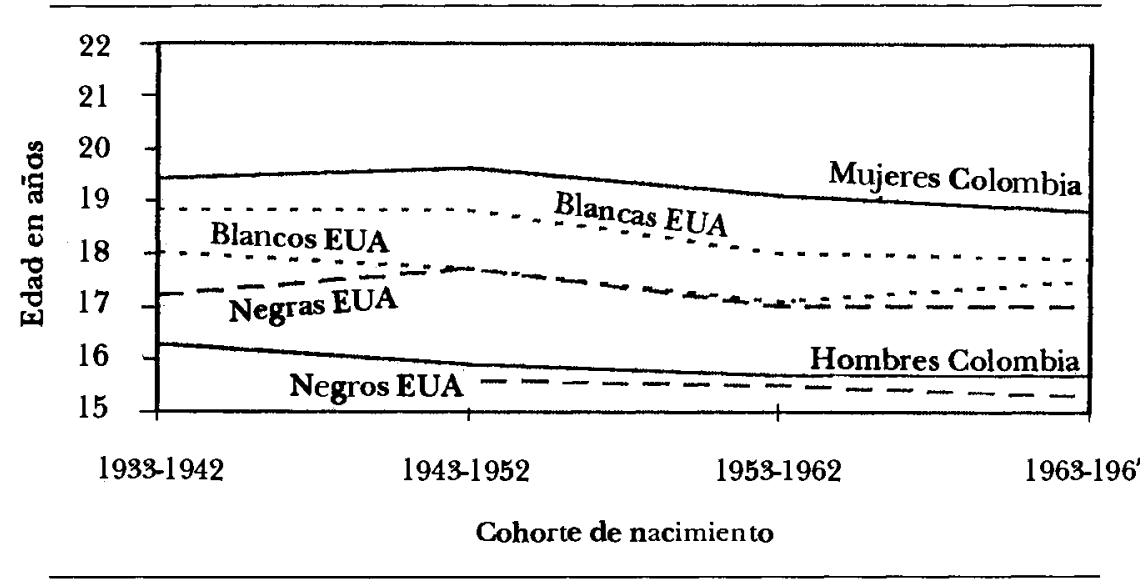

Fuente: Colombia, Isscol/93; Estados Unidos, Laumann et al., 1994.

En detalle, las diferencias hombre-mujer de Colombia para la serie Colombia-Francia, leyendo de izquierda a derecha en la gráfica, y haciendo cálculos a partir del cuadro 1 , son en años: 2.4, 3.3, 3.5, 3.4, 2.7 y 1.9, para una diferencia promedio de 2.9 años. En cambio, para Francia las diferencias son, respectivamente, 2.9, 1.8, 1.0, 0.8, 0.7, 0.9 con un promedio de 1.4 años. La serie Colombia-EU tiene estas diferencias seriadas: $3.1,3.7,3.4$, y 3.1 con promedio 3.3 para Colombia; $0.8,1.1,0.9$, y 0.4 con promedio 0.8 para la muestra de blancos y 2.1 , 1.5 , y 1.7 con promedio de 1.7 para la muestra de negros. Las diferencias en Francia y Estados Unidos tienden a decrecer a medida que las cohortes se hacen másıjóvenes, con variaciones interesantes entre los países y grupos comparados; en cambio para Colombia la diferencia se mantiene estable e incluso se hace mayor en el extremo derecho de la gráfica 2.

c) Es interesante el contraste sociorracial sólo posible en Estados Unidos, en donde la variable race en una encuesta es usual y aceptable, cosa que no ocurre en Francia y Colombia: las mujeres blancas tienen la curva de promedios más alta, aproximadamente un año inferior a la de las mujeres colombianas y la distancia entre ellas y los hombres blancos es equivalente a la distancia entre las mujeres negras y los 
hombres negros, sólo que esta categoría sociorracial está sistemáticamente más baja que el grupo blanco. Los varones negros son los que se reportan como sistemáticamente más precoces, ligeramente por debajo de los ya muy precoces hombres colombianos.

d) En el caso francés y colombiano de la gráfica 1 se observa una tendencia marcada al descenso en el tiempo histórico del promedio de edad de la iniciación sexual interactiva con puntos de quiebre descendente que merecen ser observados con detalle para hombres y mujeres. Para enriquecer el análisis veamos no sólo las cohortes, sino la década contextual en que se da la iniciación (escrita entre paréntesis en el eje de las $X)$. Los hombres franceses acusan un primer quiebre de descenso cuando se inician en la década (55-65) y mantienen el descenso en la siguiente década (65-75), el cual se detiene en la década (75-85). Como los hombres, las mujeres francesas acusan un descenso muy marcado a partir de la iniciación en la década (55-65) que se prolonga en la década (65-75) a tal punto que su promedio casi se asimila al de los hombres de su país; a partir de entonces se mantiene un promedio constante. Los hombres colombianos tienen un fuerte descenso en la década (55-65) y luego acusan un descenso leve que mantiene el promedio por debajo de los 16 años. La mujer colombiana, que inicia su curva en un promedio más bajo que la mujer francesa, mantiene su edad de iniciación constante en los 19 años hasta la década 75-85 en que acusa un descenso marcado que corta no sólo la edad promedio de la mujer francesa sino la de los hombres franceses.

$e$ ) En la anterior descripción puede haber una falacia: en las cohortes más jóvenes puede haberse inducido artificialmente un descenso en el promedio. Por ejemplo, los nacidos en 1972-1973 en Colombia pudieron haber visto recortada su posibilidad de expresión en la variable "edad al ingreso a la vida sexual adulta" por el hecho de haberse hecho la encuesta en 1993, fecha que les anula la posibilidad de reportar experiencias de iniciación por encima de los 20-21 años. En la distribución general de esa variable obtuvimos que por lo menos $15 \%$ se inició por encima de tal edad (percentil 0.85). El mismo sesgo puede afectar a las cohortes 67-71, aunque en menor grado y, desde luego, a los casos franceses y estadunidenses. Para el caso colombiano se hizo un control, comparando las curvas con muestras recortadas que pusieran en igualdad de circunstancias a todas las cohortes: el efecto de descenso se mantuvo en las cohortes más jóvenes, aunque disminuyó (no se muestran los datos). Podemos en tonces concluir que, descontando un efecto artificial de la encuesta sobre estas cohor- 
tes, el descenso general reportado en el punto $d$ ) se mantiene, aunque morigerado.

\section{El número de parejas sexuales en el año anterior.}

La pregunta en la encuesta colombiana era “¿Con cuántas personas aproximadamente ha tenido usted relaciones sexuales en el último año?" En la encuesta estadunidense, con la cual haremos estrecha comparación, la pregunta era "Recordando los 12 meses anteriores, ¿con cuántas personas, incluyendo hombres y mujeres, tuvo usted actividad sexual, aunque fuera una sola vez?". "Actividad sexual" había sido ya definida implícitamente como sexual intercourse, como se dijo en la sección anterior. La publicación francesa trae pocos detalles sobre esta variable, pues sus análisis se refieren con detalle a periodos de referencia distintos de los del "año anterior", particularmente a "las últimas cuatro semanas". Hay allí, pues, datos no comparables.

La variable bajo estudio es uno de los casos en que se requiere observar y comparar toda la distribución de la variable, pues las usuales medidas de tendencia central (moda, mediana, y media) coinciden en el valor 1.0 en la mayoría de los grupos comparados, y no reflejan lo interesante de los valores iguales o superiores a "2 parejas" que son los que realmente importan como indicadores de estilos diferenciales de la conducta sexual. Siguiendo la recodificación estadunidense la variable se presenta con los siguientes valores: " 0 ", " 1 ", “2 a 4 ", y "5 o más" parejas. Además de los valores numéricos que traen los cuadros 2 y 3 , se presentan para ayuda del análisis comparativo las gráficas 3, 4 y 5 . El estudio de Estados Unidos trae información puntual para otros países europeos, aparte de Francia, que aprovechamos para ampliar nuestro rango comparativo.

Aunque la modalidad de columnas sería la ortodoxa para graficar este tipo de variables discretas nos hemos tomado la libertad de utilizar curvas lineales de distribución, debidamente suavizadas, para facilitar la comparación visual de las tendencias. Téngase presente, de todos modos, que se trata de porcentajes de respuesta correspondientes a las varias categorías de respuesta ("0", "1", "2-4", "5 y más") y que estas categorías se ubican implícitamente en un continuum que va de 0 parejas a $n$.

La gráfica 3 y el cuadro 2 contrastan las tendencias de comportamiento de la variable "número de parejas sexuales en año anterior" 
CUADRO 2

Proporción de hombres y mujeres que reconocen haber tenido determinado número de parejas sexuales durante el año anterior, por países

\begin{tabular}{lrrrrr}
\hline & \multicolumn{5}{c}{ Número de parejas habidas en el año anterior } \\
\cline { 2 - 6 } Países & 0 & 1 & $2-4$ & $5+$ & $n$ \\
\hline Hombres & & & & & \\
$\quad$ Estados Unidos & 9.9 & 66.8 & 18.3 & 5.1 & 1408 \\
G. Bretaña & 13.1 & 73.0 & 12.3 & 1.5 & 8384 \\
Francia & 11.1 & 77.5 & 10.3 & 1.0 & 8942 \\
Finlandia & 4.5 & 78.4 & 18.2 & 4.5 & 897 \\
Colombia & 4.0 & 58.5 & 27.1 & 10.5 & 4828 \\
Mujeres & & & & & \\
Estados Unidos & 13.6 & 74.6 & 10.0 & 1.7 & 1747 \\
G. Bretaña & 13.9 & 79.4 & 6.4 & 0.0 & 10492 \\
Francia & 17.3 & 78.0 & 4.5 & .2 & 11104 \\
Finlandia & 8.3 & 78.6 & 10.7 & 0.0 & 881 \\
Colombia & 15.2 & 80.8 & 3.7 & .3 & 6949 \\
\hline
\end{tabular}

Fuente: para Colombia, Isscol/93; para otros países Laumann et al., 1994: table 5.4 C.

CUADRO 3

Proporción de mujeres y hombres que reconocen haber tenido determinado mímero de parejas sexuales durante el año anterior, por estado civil y país de residencia

\begin{tabular}{|c|c|c|c|c|c|c|}
\hline \multirow[b]{4}{*}{ Grupos de edad } & \multicolumn{6}{|c|}{ Estado civil y país } \\
\hline & \multicolumn{2}{|c|}{ Soltero } & \multicolumn{2}{|c|}{ Casado } & \multicolumn{2}{|c|}{ Separado } \\
\hline & Estados & & Estados & & Estados & \\
\hline & Unidos & Colombia & Unidos & Colombia & Unidos & Colombia \\
\hline \multicolumn{7}{|l|}{ Mujeres } \\
\hline \multicolumn{7}{|l|}{$18-29$} \\
\hline 0 & 12.9 & 19.8 & 0.0 & 0.5 & 2.0 & 29.7 \\
\hline 1 & 56.6 & 67.2 & 96.0 & 98.6 & 58.0 & 54.6 \\
\hline $2-4$ & 24.2 & 12.2 & 3.0 & .9 & 33.3 & 14.1 \\
\hline $5+$ & 6.2 & .8 & 1.0 & 0.0 & 5.9 & 1.6 \\
\hline $\mathrm{N}$ & 256 & 509 & 201 & 633 & 51 & 185 \\
\hline \multicolumn{7}{|l|}{$30-44$} \\
\hline 0 & 37.3 & 36.5 & 1.3 & 1.2 & 18.9 & 44.9 \\
\hline 1 & 42.4 & 56.1 & 96.4 & 97.7 & 58.3 & 45.7 \\
\hline $2-4$ & 17.8 & 6.3 & 2.1 & 1.1 & 21.7 & 8.3 \\
\hline $5+$ & 2.5 & 1.1 & .2 & 0.0 & 1.1 & 1.1 \\
\hline $\mathrm{N}$ & 118 & 189 & 473 & 1101 & 180 & 372 \\
\hline \multicolumn{7}{|l|}{$45-59$} \\
\hline 0 & 64.9 & 76.5 & 7.3 & 10.7 & 54.1 & 78.0 \\
\hline 1 & 27.0 & 19.1 & 91.3 & 89.2 & 36.1 & 19.9 \\
\hline $2-4$ & 8.1 & 4.4 & 1.4 & 0.2 & 9.0 & 1.8 \\
\hline $5+$ & 0.0 & 0.0 & 0.0 & 0.0 & 0.8 & .3 \\
\hline $\mathrm{N}$ & 37 & 68 & 275 & 629 & 133 & 396 \\
\hline
\end{tabular}


(Conclusión cuadro 3)

\begin{tabular}{|c|c|c|c|c|c|c|}
\hline \multirow[b]{3}{*}{ Grupos de edad } & \multicolumn{6}{|c|}{ Estado civil y país } \\
\hline & \multicolumn{2}{|c|}{ Soltero } & \multicolumn{2}{|c|}{ Casado } & \multicolumn{2}{|c|}{ Separado } \\
\hline & $\begin{array}{r}\text { Estados } \\
\text { Unidos }\end{array}$ & Colombia & $\begin{array}{c}\text { Estados } \\
\text { Unidos }\end{array}$ & Colombia & $\begin{array}{c}\text { Estados } \\
\text { Unidos }\end{array}$ & Colombia \\
\hline \multicolumn{7}{|l|}{ Hombres } \\
\hline \multicolumn{7}{|l|}{$18-29$} \\
\hline 0 & 14.6 & 7.4 & .8 & 0.0 & $\#$ & 6.1 \\
\hline 1 & 40.7 & 29.0 & 90.9 & 79.6 & \# & 33.3 \\
\hline $2-4$ & 30.5 & 44.3 & 5.8 & 16.0 & \# & 36.4 \\
\hline $5+$ & 14.2 & 19.3 & 2.5 & 4.0 & $\#$ & 24.2 \\
\hline $\mathrm{N}$ & 302 & 1168 & 121 & 274 & 21 & 33 \\
\hline \multicolumn{7}{|l|}{$30-44$} \\
\hline 0 & 23.1 & 14.5 & .6 & 0.0 & 14.0 & 8.9 \\
\hline 1 & 34.0 & 30.9 & 93.3 & 78.4 & 40.2 & 29.1 \\
\hline $2-4$ & 35.4 & 35.3 & 5.6 & 17.6 & 39.2 & 40.5 \\
\hline $5+$ & 7.5 & 19.3 & 0.6 & 4.0 & 6.5 & 21.5 \\
\hline $\mathrm{N}$ & 147 & 249 & 356 & 848 & 107 & 79 \\
\hline \multicolumn{7}{|l|}{$45-59$} \\
\hline 0 & \# & 17.7 & 3.7 & 2.7 & 30.1 & 16.7 \\
\hline 1 & \# & 17.7 & 91.5 & 79.2 & 45.2 & 33.3 \\
\hline $2-4$ & \# & 46.8 & 3.7 & 13.5 & 23.3 & 33.3 \\
\hline $5+$ & \# & 17.7 & 1.2 & 4.6 & 1.4 & 16.7 \\
\hline $\mathbf{N}$ & 15 & 62 & 246 & 586 & 73 & 66 \\
\hline
\end{tabular}

\# = Número de casos inferior a 30 en la categoría de edad. Fuente: Colombia, Isscol/93; EU, Laumann et al., 1994.

GRÁFICA 3

Proporción de hombres y mujeres que reconocen haber tenido determinado número de relaciones sexuales en el año anterior, por países
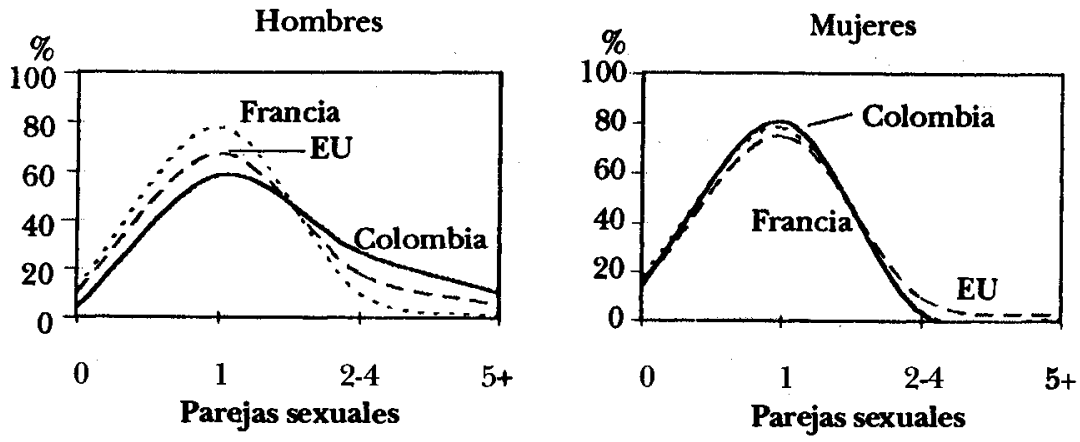


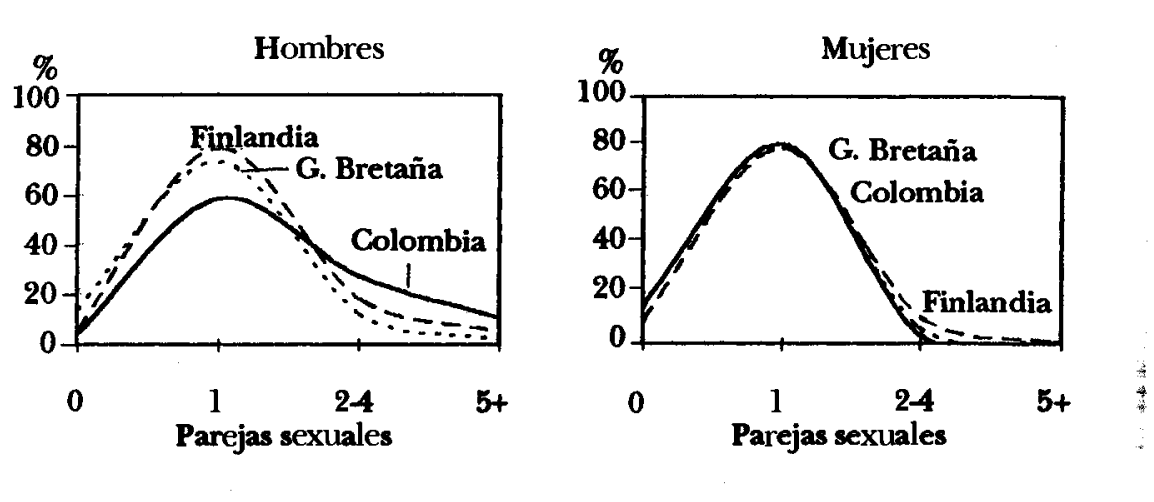

Fuente: Colombia, Isscol/93; Otros países, Laumann et al., 1994: t. 5, 4C.

en hombres y mujeres de Colombia frente a similares de EU, Francia, Gran Bretaña y Finlandia. En el eje de las $Y$ de la gráfica 3 se observan los porcentajes de autoclasificación de los entrevistados en cada uno de los valores discretos "continuizados" de número de parejas: " 0 ", "1", "2 a 4", y "5 y más". La observación detenida de estas gráficas, y la confrontación del detalle numérico en el cuadro 2, permiten hacer los siguientes comentarios descriptivos:

a) El notable dimorfismo en la expresión de la sexualidad que se observó ya entre hombres y mujeres colombianos se reafirma, contrastando fuertemente con el dimorfismo menor hallado en los otros países. En efecto, si reagrupamos las categorías " 0 y 1 pareja" por un lado como expresión de un estilo de conducta unipareja y " 2 o más parejas" por el otro como expresión de otro estilo más multipareja) encontramos que la diferencia para Colombia es de 32.5 puntos porcentuales, mientras Estados Unidos tiene 11.5, Gran Bretaña 7.2, Francia 6.7 y Finlandia 4.0. Este contraste puede comprobarse visualmente en la

${ }^{7}$ Este feo neologismo y su contraparte multipareja intentan, mal que bien, evitar expresiones como "sobrio, no sobrio" que tienen una connotación moralizante acrecida durante siglos. La interpretación usual periodística de la idea detrás de está variable es la del "conservadurismo" versus "liberalidad" o "permisividad" sexual, y la interpretación usual salubrista en contextos de control de sida es el muy sesgado apelativo de "promiscuo" o "no promiscuo". La idea de sobriedad/no sobriedad es tomada del concepto de sophrosine (temperancia) propia de la chrésis aphrodisión (uso de los placeres) usado por 


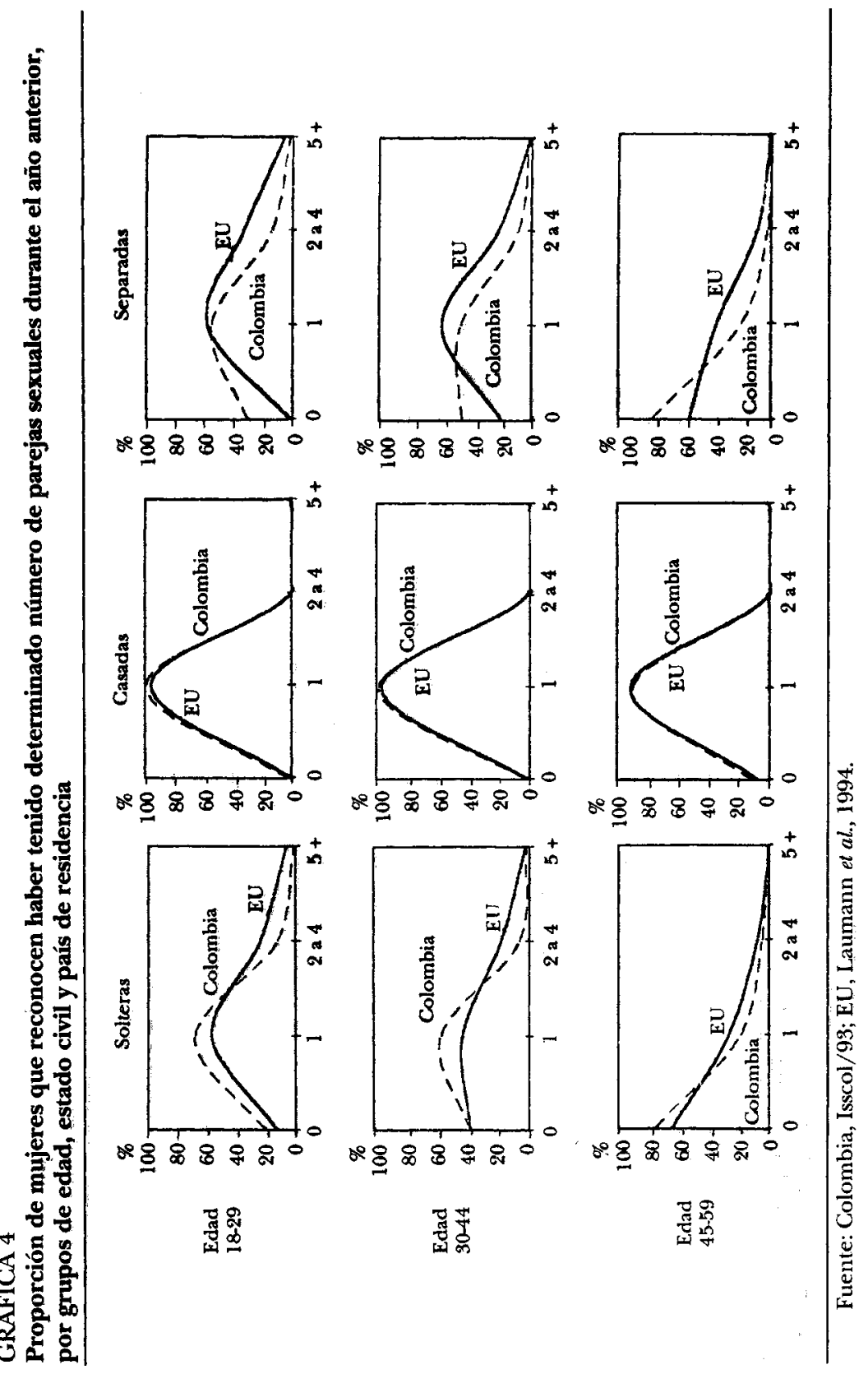




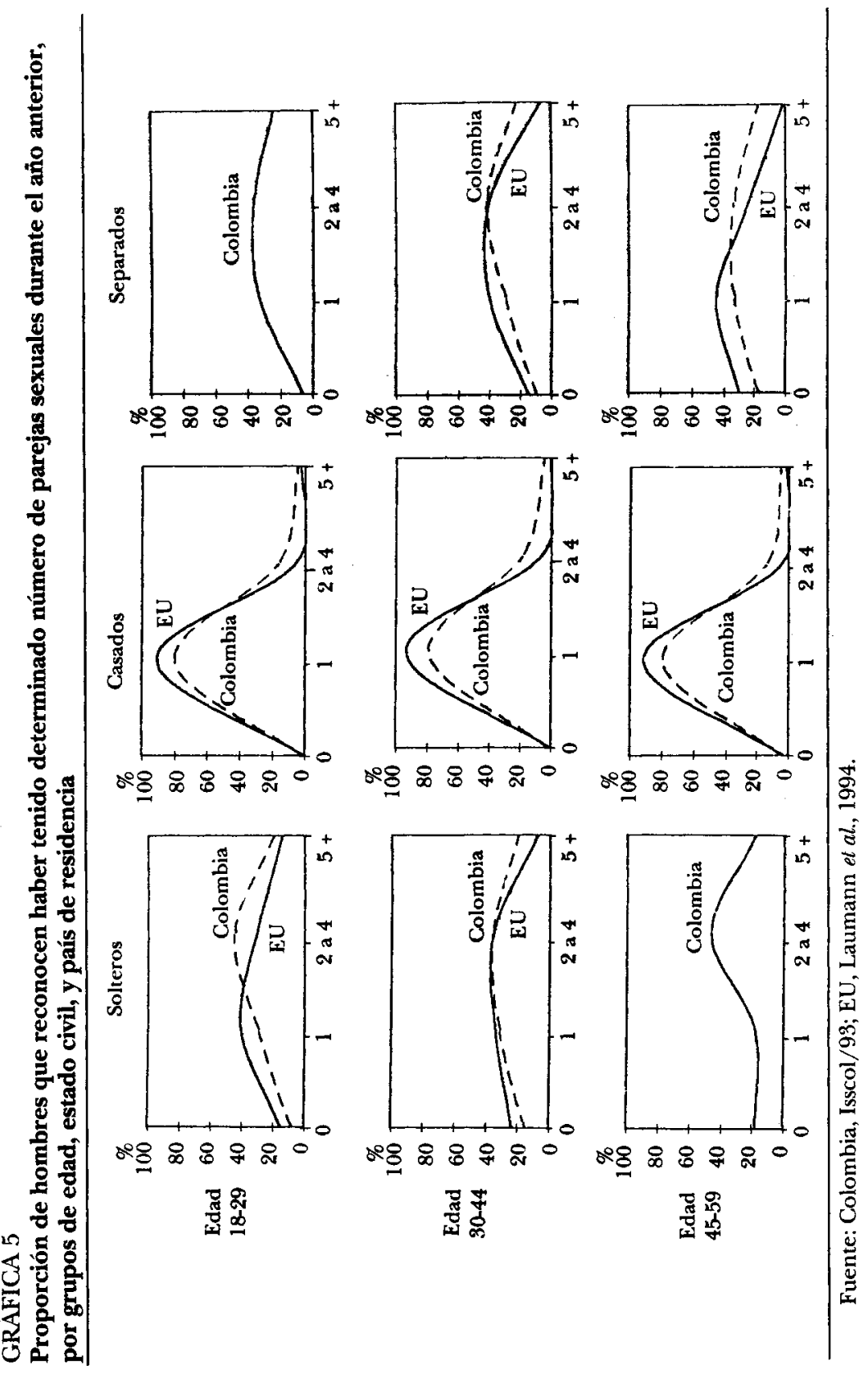


gráfica comparando, por países, las curvas de los hombres con las correspondientes curvas femeninas.

b) $\mathrm{Al}$ hacer en la gráfica 3 el ejercicio visual sugerido en el párrafo anterior se puede comprobar que las curvas femeninas, para todos los países, incluyendo Colombia, son visualmente coincidentes: las variaciones se detectan sólo en el cuadro 2, porque son pequeñas. Estas variaciones indican: $i$ ) que las diferencias entre las mujeres de los diferentes países son menores, comparadas con las de los hombres; ii) que el orden descendente de preferencia multipareja (definida como admitir haber tenido 2 parejas en el año anterior) es el siguiente: Estados Unidos (11.7\%), Finlandia (10.7), Gran Bretaña (6.4\%), Francia (4.7\%) y, por último Colombia (3.7\%). La categoría de "5 y más pare:jas" no revela mucho en cuan to a variación interpaíses, pero sí en cuanto a la tendencia general de las mujeres hacia la preferencia unipareja, pues los porcentajes son de 0 o muy cercanos a él. En resumen: las mujeres de Colombia comparten la preferencia unipareja generalizada de las mujeres de los otros países si se mira la categoría "5 y más parejas", y lo hacen mucho más si se mira la categoría " 2 parejas”. Desde luego, este rasgo acentúa el dimorfismo de la sexualidad colombiana pues, como se verá, los hombres colombianos aparecen como los más multipareja de todos los grupos comparados.

c) Al comparar las curvas de comportamiento masculino se concluye que definitivamente los hombres colombianos aparecen como los de mayor tendencia multipareja, tanto si se mira la categoría de "2 parejas" o la de "5 y más": en ambas, el primer lugar lo ocupa Colombia, seguido por Estados Unidos, Finlandia, Gran Bretaña y Francia. Colombia se destaca solitario en un puntaje porcentual alto, luego en un puntaje mediano se ubican Estados Unidos y Finlandia, y en el tercer grupo encontramos a Gran Bretaña y Francia (véase cuadro 2 para los detalles numéricos).

Es posible con los datos disponibles de Estados Unidos y Colombia observar con mayor detalle los hallazgos anteriores, haciendo una comparación para hombres y mujeres, por grupos de edad y de con-

Foucault (1984) con referencia a los griegos de la época clásica y convertida luego por el cristianismo en la virtud de la templanza (de allí su fuerte valoración moral). Es de advertir que aquí se trata sólo de describir el número de parejas sin considerar las implicacio nes de estos estilos de vivencia erótica. No se trabaja tampoco el importante dato de la variedad "plástica" de las prácticas, que sería el complemento cualitativo del dato cuantitativo de parejas, ni el de otras implicaciones sociales como la extraconyugalidad, la fidelidad, o psicológicas como la significación o importe vivencial de tales encuentros. 
dición de los sujetos frente a la institución del matrimonio. El cuadro 3 y las gráficas 4 y 5 presentan los resultados. Sobre estos datos se puede comentar descriptivamente lo siguiente:

1) Las mujeres solteras colombianas de todas las edades acusan un comportamiento más unipareja que sus homólogas estadunidenses (gráfica 4). Las curvas de los dos países son similares en su forma, pero las correspondientes a las colombianas son sistemáticamente más corridas hacia la izquierda y hacia arriba en el cuadrante superior izquierdo de la gráfica, y hacen lo inverso en el cuadrante inferior derecho.

2) Las mujeres casadas colombianas y estadunidenses tienen un comportamiento visualmente similar (gráfica 4) y cuando se leen las cifras (cuadro 3) se encuentra que de manera sistemática las colombianas aparecen como más uniparejas. Con muy pocas excepciones, estas mujeres, colombianas y estadunidenses se ubican en las categorías de " 0 " y particularmente de " 1 ".

3) Las mujeres separadas replican el patrón ya hallado para las solteras (preferencia unipareja femenina colombiana), aunque se observa que la categoría " 0 " parejas aumenta en proporción para ellas, lo cual a su vez acentúa la restricción.

4) Los hombres solteros colombianos (gráfica 5) ofrecen el comportamiento inverso de sus mujeres, pues se ubican sistemáticamente en el polo de preferencia opuesta, resultando por ello mucho más multipareja que sus homólogos estadunidenses. La categoría de edad 44-59 no presenta información para Estados Unidos, por escasez de casos (valor de la celda inferior a $n=30$ ). Es notable esta categoría en los colombianos por ser el único caso que tiene una moda de la distribución muy claramente ubicada en el polo "no-sobrio" ("2 parejas").

5) Los hombres casados estadunidenses se ubican mayoritariamente en las categorías " 0 " y sobre todo en " 1 ", dejando en frecuencia 0 , o en su cercanía, las categorías iguales o mayores que 2 . Aun en este caso los colombianos se revelan más multipareja, pues las proporciones correspondientes a esta preferencia son dignas de consideración, tanto visual como numéricamente (cuadro 3). Este patrón es sistemático en las tres categorías de edad.

6) Finalmente, los hombres separados colombianos replican el patrón de los solteros, tanto en su distribución frente a los distintos valores de la variable, como en su exceso multipareja frente a los estadunidenses. La única novedad digna de anotar es que en la categoría de edad 44-59, no sé, la moda vuelve a ser en "0-1", no en "2 parejas" como 
ocurrió con los solteros. No sobra anotar que en la categoría de edad 18-29 no hay dato para Estados Unidos, por escasez de casos.

\section{Discusión}

\section{Sintesis de los hallazgos}

Parece haber evidencia de los siguientes rasgos de la conducta sexual de los colombianos como conjunto nacional, en cuanto ella está insinuada por la proporción de quienes dicen no haber tenido ninguna experiencia sexual previa a la encuesta y representada por dos variables importantes de encuesta, la edad de la iniciación a la vida sexual interactiva y el número de parejas habidas en el año anterior a la entrevista: $i$ ) hay un marcado dimorfismo que ubica a la mujer y al hombre colombianos en los polos opuestos más distantes en cuanto al continuum de precocidad y de preferencia uni o multipareja de la conducta sexual dentro de la totalidad de los grupos comparados (exceptuando los varones negros de Estados Unidos); ii) esa polarización hace que en general la mujer colombiana aparezca sistemáticamente más unipareja en su conducta que sus homólogas de Estados Unidos y Francia (y de Gran Bretaña y Finlandia, con las cuales hubo una comparación puntual) $\mathrm{y}$, al contrario, el hombre colombiano aparezca sistemáticamente como más multipareja que sus homólogos de los países comparados; iii) las diferencias hombre-mujer existen en los otros países pero no son tan marcadas como entre los colombianos, y en éstos no se amenguan a medida que las cohortes se hacen más jóvenes, fenómeno que sí se observa en los otros países; iv) se observa para los colombianos y para los franceses un descenso histórico en la edad promedio de la iniciación en la sexualidad interactiva de tal modo que las cohortes más jóvenes presentan promedios más bajos, pero manteniendo en el caso colombiano la gran distancia hombremujer; $v$ ) se observan variaciones en Francia, Estados Unidos y Colombia en cuanto a la década en que ocurrió el quiebre de descenso en la edad promedio de iniciación, lo cual puede estar relacionado con el con texto coyuntural en que ella ocurría y con los vaivenes de la llamada revolución sexual; vi) en el descenso en la edad promedio de iniciación las mujeres colombianas aparecen más precoces que las francesas a partir del periodo cronológico 85-88; vii) se observa una variación sociorracial interesante en Estados Unidos que 
apunta a patrones diferentes de sexualidad entre los blancos y los negros; viii) los varones negros de Estados Unidos aparecen como ligeramente más precoces que los mismos varones colombianos, los cuales -como se ha dicho-aparecen en general como los más precoces y multipareja de todas las categorías comparadas de las muestras.

La pregunta analítica central en esta discusión es ¿qué significan estos datos, tomados como indicadores de un fuerte dimorfismo hombre-mujer en precocidad y preferencia de número de parejas, para una descripción comprensiva de lo que llamaríamos "la sexualidad que se han construido los colombianos"? Se hace enseguida una serie de comentarios que tratan de introducir elementos críticos que ayudan a entender la situación planteada o a perfilar hipótesis que requieren adicional estudio. Los comentarios se agrupan en dos conjuntos de acuerdo con el énfasis metodológico (cómo se estudia la cuestión') o sustantivo (qué se puede concluir) que predomina en el debate.

\section{Aspectos metodológicos}

\section{El alcance de los datos}

El primer comentario tiene que ver con asuntos de validez veritativa ${ }^{8}$ que tiene la información que estamos analizando. No podemos, sin más, creer que los hallazgos que tenemos enfrente, así estén expresados en números con cifras decimales de precisión, representen la conducta que en realidad tienen los colombianos y los de las otras nacionalidades en el campo sexual. Lo máximo que podemos decir es que esos datos representan lo que los entrevistados, colombianos o no, dijeron de su conducta en una situación de diálogo sujeto a una doble constricción: i) la que impone la reticencia cultural sobre un tema considerado tabú, o por lo menos privado, y $i$ ) la que se deriva de una situación de encuesta.

\footnotetext{
${ }^{8}$ Se trabaja aquí con los conceptos de cuatro formas de validez que pueden tener los enunciados científicos y no científicos, según la pragmática lingüística: de comprensibilidad, de verdad, de veracidad y de rectitud o de legitimidad. En el presente caso tenemos que vérnosla con la cuestión de la verdad de nuestras conclusiones. Véase Schlieben-Lange (1987: 83-149) y Habermas (1987: 391-432). No olvidemos, sin embargo el sabio consejo dado hace ya mucho tiempo por Bateson (1993 [1946]: 74): "El antrópologo no debe preguntarse seguidamente: ¿La declaración de este hombre es objetivamente cierta?, sino que debe buscar aquellos datos que le permitan colocar la declaración de ese hombre en una situación cultural".
} 
i) Sobre la primera restricción (tema tabú) llama la atención la dificultad que reportan los investigadores estadunidenses para trabajar abiertamente por encuesta el tema de la sexualidad en ese país: tuvieron que disfrazarlo con términos eufemísticos para no ofender la sensibilidad de ciertos políticos y sectores sociales que tenían el control de los fondos estatales con que se pensaba realizar el estudio aduciendo una intromisión inaceptable en los dominios privados (Laumann et al., 1994: 35-73). Esta dificultad respecto al discurso público sobre la sexualidad no ha sido reportada para Colombia en las encuestas que nuestro Grupo de Trabajo en la Universidad del Valle ha revisado hasta el momento, al menos en la forma exagerada que aparece en Estados Unidos. Aunque como en otras partes, también en Colombia se observa la reticencia privada para hablar de las propias intimidades sexuales ante extraños. Sin embargo, las actuaciones recientes de los líderes públicos que se han expresado con motivo de un Programa Nacional de Educación Sexual y de la publicación por dos periódicos de circulación nacional de sendas series educativas sobre el tema, con pocas excepciones se alinean en favor de un tratamiento abierto y desinhibido de estos temas. El informe francés hace pensar que la actitud pública sobre la generación de la encuesta fue parecida a la de Colombia, es decir, no problemática.

ii) Sobre la segunda restricción (situación de habla de una encuesta) hay que anotar que las ventajas de este recurso técnico, en especial su serialidad, su replicabilidad, y su capacidad de resolver exigencias numéricas base de inferencia, se ven descompensadas por la artificialidad de la situación de habla directa en que se desenvuelve, que permite más subterfugios de evasión que una situación de entrevista etnográfica. Ésta, además de suponer un contexto más propicio para la autenticidad de la comunicación, permite trabajar en el triple plano de información, evocación y reflexión (Kofes, 1992) que hacen muy cercano el discurso entre investigador e informante al de situaciones de habla cotidianas.

El recurso a otras modalidades de investigación puede darnos una idea de cuán distantes estamos de lo actuado, a partir de la triangulación metodológica de técnicas para obtener los datos. Para el caso de la sexualidad los aportes historiográficos, que intentan leer indicios sobre el ejercicio de la sexualidad entre las líneas de lo dicho formalmente por el documento-monumento (Le Goff, 1991: 227240) sobre ciertos productos institucionales de la misma, resultan particularmente importantes. Se trata de un recurso indirecto, cerca- 
no a los métodos abductivos (Eco, 1989), que parece ser el camino más eficaz en trabajos sobre este tema doblemente constreñido. Por ello contamos hoy con un creciente volumen de información historiográfica que pone a la historia en bastante ventaja sobre disciplinas como la sociología y la antropología.

De todos modos, aun con estas limitaciones, la encuesta aporta elementos de juicio que permiten por lo menos plantearse preguntas interesantes sobre el erotismo y el amor en una sociedad determinada y trasladarnos a un estado de cosas que no existía antes de las encuestas (bien realizadas). George Bataille, quien en su libro sobre el erotismo (1968) aparece como uno de los adalides de la idea de que las vivencias interiores constitutivas del erotismo, tan afines a lo sagrado por aquello de la transgresión y la regresión a la continuidad de la vida fundamental, son refractarias al tratamiento de la ciencia, termina utilizando de manera muy sugerente y productiva las estadísticas del informe Kinsey sobre la frecuencia semanal reportada de los coitos y su distribución de acuerdo con la clasificación por grupos ocupacionales. El argumento de este autor es que, a pesar de la inefabilidad de la vivencia erótica, es posible aproximarse a ella combinando el gran número de respuestas que, si la encuesta ha sido cuidadosamente diseñada y ejecutada, aportan datos sobre hechos que fueron observados desde adentro por aquellos que los vivieron y que hablan sobre ellos.

Se puede postular que esta primera aproximación, desde afuera pero por medio de la anamnesis, es válida en tanto apela a la ley de los grandes números que versan sobre hechos puntuales de habla creados por sus vivenciadores. A partir de esta base se pueden dar otros pasos de investigación. Por ejemplo, pueden usarse los análisis masivos de los ensayos cuestionario (al estilo de los relatos suscitados por Hite) en que se da vía libre al intento subjetivo de hacer narrativas libres sobre la propia vivencia erótica, prestando desde luego debida atención a la representatividad de los ensayos (véase Giddens, 1992: 135), problema serio en los estudios de Hite (véase Stone, 1995). El trabajo más directamente etnográfico de la entrevista a profundidad, y sobre todo los procedimientos indirectos y abductivos, completarían el espectro de recursos de investigación. Al término de este recorrido cualitativo podrian usarse de nuevo las encuestas para someter a prueba determinadas hipótesis que se han logrado retinar con otras metodologías y son susceptibles de ser sometidas a este tipo especializado de tratamiento. Es obvio que en el presente nos encontramos usando las encuestas como faros exploratorios en un campo que apenas comienza a conocerse. 


\section{La incomparabilidäd de los datos}

Salvados los anteriores escollos metodológicos entramos al siguiente. Se puede argüir que las diferencias encontradas entre Colombia y los otros países no son tales, pues en rigor las tres encuestas no son comparables: la colombiana fue presencial y la hicieron mujeres, la estadunidense, también presencial, la hicieron hombres y mujeres, y la francesa fue realizada por teléfono. Por el momento la sociología no dispone de elementos de "jurisprudencia" suficientes para aislar y evaluar de manera satisfactoria los efectos de estas modalidades técnicas ni del género (y de otras características personales del entrevistador) sobre lo dicho en las entrevistas de encuesta que versan sobre la sexualidad.

Podemos sin embargo adelantar una opinión. Actuando con rigor, ninguna situación de habla, y menos la totalmente informal produce resultados comparables. Precisamente la encuesta, con su estandarización de ciertos parámetros lingüísticos intenta crear una base mínima comparativa. Es decir, que el efecto negativo de la encuesta como situación de habla que agudiza el problema cultural de decir algo sobre el sexo (véase supra) compensaría su desventaja con la de una mínima estandarización que permite comparaciones. Esta estandarización no se logró del todo en las preguntas de campo de las tres encuestas comparadas, pues a fin de cuentas se apeló al sentido común para la comprensión de las preguntas. Por ejemplo, se supuso que la gente entiende en su idioma qué es un sexual intercourse, un rapport sexuel, o una relación sexual y que hay comparabilidad entre los miembros de la comunidad lingüística y entre las comunidades lingüísticas.

De hecho falla la exacta correspondencia de los dos entres pero se acepta que hay por lo menos cierto núcleo mínimo de correspondencia y que éste es suficiente para los propósitos del estudio. Hilar más delgado, lo que es posible, nos introduciría en un nivel de crítica para el cual el campo novel de investigación en que nos encontramos resulta aún inmaduro. Más aún, esa exactitud puede resultar irrelevante, pues la mínima comparabilidad asegurada puede ser adecuada para los propósitos del estudio. Este argumento es una consecuencia del hecho de que la encuesta sigue siendo producto de una situación de habla. Y de todos modos, sigue en pie el aforismo de que es mejor una información sometida a alguna crítica que ninguna o que simples suposiciones. 
Aspectos sustantivos sobre la sexualidad de los colombianos

Tenemos pues que, con las salvedades arriba anotadas, la conducta sexual de los colombianos descrita por dos importantes variables de encuesta nacional arraja un perfil que llama poderosamente la atención tanto si se analiza la encuesta por sí misma como si se compara con datos también de encuesta nacional procedentes de otros países. No tenemos dudas acerca de la seriedad y competencia con que fueron diseñadas y ejecutadas las tres encuestas. Las limitaciones que se han mencionado son inherentes a la filosofía misma de este medio de investigación y la información por él generada se puede usar dentro de límites precisos.

La encuesta colombiana pone de manifiesto una polarización hombre-mujer en los dos rasgos de la conducta analizada que hace que (a) resulte interesante por sí misma y (b) se haga más interesante al establecer comparación con los otros países, pues los varones colombianos resultan sistemáticamente los más precoces y multipareja de todos (exceptuando a los negros de Estados Unidos) y las mujeres las menos entre todos y todas. El dato (b) permite hablar con propiedad de una disparidad exagerada. Por falta de información comparativa para el dato $(b)$ nos centraremos en el dato (a), que es el hallazgo radical.

La disparidad exagerada demanda explicación, o desvirtuación, puesto que a más de la inconsistencia psicosocial que implica el que en una misma cultura hombres y mujeres, los dos componentes fundamentales del juego erótico, tengan conductas reales tan divergentes, tal inconsistencia es también lógica, pues -descontado el margen relativamente estrecho de las relaciones homoeróticas y otros casos marginales- los hombres colombianos hacen lo que dicen hacer con las mujeres colombianas. Procedamos a reflexionar críticamente sobre esta posible inconsistencia recapacitando sobre las dos variables.

\section{Posible anomalía del perfil colombiano sobre precocidad sexual}

Observemos en primer lugar la precocidad en la iniciación sexual, y en particular el hecho de que los varones colombianos aparezcan como muy precoces y sus mujeres como muy tardías, a la luz de una hipótesis interpretativa lanzada por el estudio francés para los hallazgos franceses, que no distingue entre hombres y mujeres para este propósito preciso: 
Aparece así que los individuos (hombres y mujeres) más precoces sexualmente tienen una vida más compleja y menos "regulada". Tienen más parejas sexuales que los otros, particularmente durante la adolescencia, pero también durante todos los periodos de su vida, incluido el conyugal. Son ellos los que tienen más parejas extraconyugales, que se casan menos, y que conocen más separaciones. Tienen por lo demás el repertorio más diversificado en términos de experiencia y de prácticas sexuales. En fin, más que los otros, piensan que pueden separar sexualidad y sentimiento. Inversamente, los individuos cuya iniciación ha sido tardía presentan un perfil mucho más tradicional. Han tenido menos parejas antes de vivir conyugalmente y menos parejas extraconyugales. Con mayor frecuencia han permanecido siempre con el mismo cónyuge, y aun con la misma pareja sexual. Su repertorio sexual es menos extenso. Se resisten a separar pareja, sexualidad y sentimiento. Los primeros se caracterizan por una capacidad de mirar sus relaciones sexuales por fuera de todo compromiso amoroso; la actividad sexual puede así aparecerles como una experiencia aparte. Los segundos, en cambio, no consideran la sexualidad por fuera de las relaciones amorosas o conyugales en donde se inscribe; ella no aparece por tanto como una actividad autónoma (Bozon, 1993: 1348).

Se postula, pues, sin distinguir entre hombres y mujeres, una correlación entre la precocidad y constelaciones conductuales posteriores que reflejan modos contrastantes de organización del eros. ${ }^{9}{ }_{¿}$ Será que, en términos de grandes números y tendencias, la correlación entre precocidad y modo concreto como se organiza la vida erótica es validable en Colombia de manera general, y de manera particular si se hace una comparación entre hombres y mujeres? Los datos franceses parecen sustentar grosso modo la hipótesis para la población francesa como conjunto global (Bozon, 1993). En Colombia tuvimos oportunidad de realizar un análisis sobre la vulnerabilidad al sida, a partir de ciertos indicadores gruesos de la organización del eros recogidos por encuesta, y se pudo advertir que hay ciertos indicios confirmatorios de la hipótesis cuando se introduce la diferenciación hombre-mujer: los sujetos más precoces (hombres) tienen más vulnerabilidad que los tardíos (mujeres) (Sevilla et al., 1994: 71-103). ${ }^{10}$

${ }^{9}$ Se hace referencia al concepto freudiano y marcusiano de la organización del eros mediante la represión y sublimación de los impulsos originarios, para adecuarse a las inapelables exigencias del principio de realidad y a las imposiciones de la necesidad. La antropología propone que esta organización adquiera formas diferentes, tanto en la evolución longitudinal de una misma cultura como en la comparación transversal de varias culturas. La dicotomía que presenta la hipótesis francesa, utilizando varios indicadores de regularización, es una construcción típica de una de estas formas, un homúnculo artificial, en el sentido de Schütz (Vide supra, pp. 264-267).

${ }^{10}$ En el estudio citado hacemos, además, una discusión de la vulnerabilidad espe- 
Este cuadro de inquietudes se reafirma si se considera la hipótesis empírica estadunidense sobre el efecto negativo de las experiencias de tocamientos (touching) sobre la vida sexual posterior sufridas por los preadolescentes: el perfil de los afectados por el touching aparece asociado con mayor actividad sexual posterior y mayores problemas en su ejercicio. Curiosamente, según la encuesta, en Colombia son los hombres los que más reportan haber tenido "relaciones sexuales" antes de los 13 años (edad preadolescente): la diferencia con las mu:jeres es notable, de $18.4 \%$ a 3.2 por ciento.

¿Será entonces que la sociedad colombiana ha logrado separar tanto a hombres y mujeres, que de ser válidas estas hipótesis tendríamos dos patrones básicos, uno masculino y otro femenino, que no se corresponden como teóricamente debería esperarse? $O$, retornando al cuestionamiento metodológico, ¿estamos ante un sistemático y mayúsculo efecto artificial de unas encuestas? $O$, insistiendo en la organización social de los géneros (véase nota 11), todo esto ¿es una refinada expresión de la dominación masculina (Bourdieu, 1990)? Se trata de hipótesis que resultan interesantes sea en el orden sustantivo, sobre la organización del eros y de los géneros en Colombia, sea en el orden de los procedimientos que se deben adoptar para despejar un campo que cada vez aparece como demandando intervención rigurosa de los científicos sociales.

\section{La posible anomalía en el número de parejas durante el año anterior}

La diferencia hombre-mujer respecto al número de parejas habidas durante el año anterior no hace sino refinar el argumento sobre el dimorfismo, ya formulado con referencia a la precocidad, apuntando de paso al corazón de la incoherencia lógica que nos permite hablar con propiedad de anomalía. Para ello centrémonos en las relaciones heterosexuales, pues las homosexuales, además de tener una frecuencia más baja de la que se creía ${ }^{11}$ afectan tanto a hombres como a mu-

cial que afecta a la mujer cuando se atiende a otros atributos de la posición social de la mujer, generalmente no tenidos en cuenta en los programas de prevención del sida, entre ellos la estructura generalizada de la dominación masculina, vigente en Colombia como en tantas otras sociedades (Bourdieu, 1990).

"Véase al historiador Stone (1995) para una aguda interpretación de las implicaciones políticas de 3 por ciento del homoerotismo masculino que, parece, se debe deducir de las recientes encuestas, y a Weeks (1987) para una ampliación de la apreciación al caso del lesbianismo. 
ijeres (es uno de los temas defendidos hoy en el debate sobre la sexualidad femenina liberada). Considerando al país como conjunto -recuérdese que se trata de una muestra aleatoria de cobertura nacional, con un total de 11975 casos válidos- el perfil masculino colombiano descrito y las proezas numéricas que los hombres reportan requieren de la colaboración femenina. Algo deben tener los datos de unos $u$ otras, o de unos y otras, porque la contabilidad paralela no cuadra: los hombres dicen tener más parejas que sus mujeres. Este punto ya ha sido advertido por otros autores, y los de la encuesta estadunidense presentan una serie de siete posibles explicaciones de las cuales las de la exageración verbal masculina y la miminización femenina (casos 4 y 6 de la lista en nota 13) resultan las más plausibles, a tal punto que sobre ella centraremos el intento explicativo. ${ }^{12}$

\section{En busca de explicaciones: efecto del discurso y la representación}

Afrontemos la cuestión enfocando en primer lugar la eventual falacia que se esconde en la mediación del discurso: el dimorfismo exagerado colombiano puede deberse a la existencia de significaciones diferentes de la relación sexual para hombres y mujeres ${ }^{13}$ combinada con las restricciones diferenciales que tienen para hablar de tales relaciones. La situación de habla de encuesta, asỉ desbalanceada, sería refle-

\footnotetext{
12 Laumann et al., hablan de: 1) La frecuencia de relaciones homosexuales masculinas es más alta que la de homosexuales femeninas y así se equilibran los datos; 2) Los hombres tienen relaciones con mujeres que están fuera del rango de edad captado por la encuesta; 3) Los hombres tienen relaciones con mujeres que están por fuera del rango geográfico o sociodemográfico postulado por la encuesta; 4) Hombres y mujeres pueden tener una interpretación diferente de lo que es tener relaciones sexuales; 5) Pudo haber ciertas mujeres que tuvieron muchos hombres y su respuesta numérica especial no fue captada por la encuesta; 6) Los hombres exageran hacia arriba y las mujeres hacia abajo; y 7) La diferencia en el número absoluto de mujeres frente a los hombres puede producir promedios de parejas masculinas por mujeres que explican la diferencia (1994: 185).

${ }^{13}$ Es muy pertinente el comentario de Time Magazine (17 de octubre de 1994: 50): "el abismo perceptivo entre los sexos recuerda la escena del filme Annie Hallen el que el esposo le dice a su siquiatra que él y Annie hacen el emor 'casi nunca, puede ser tres veces a la semana', y ella le cuenta, al suyo que lo hacen 'constantemente; diría tres veces por semana'". Una propuesta coherente sobre la significación diferente del erotismo para los hombres y mujeres (de Occidente) es la de F. Alberoni (1988). Tanto frelt dianos como no freudianos reconocen el desarrollo ontogenético psicosexual diferente por género, aunque saquen conclusiones opuestas del mismo fenómeno. Véase Giddens (1992: 148-157), y Badinter, 1993 para un resumen de estas posiciones.
} 
jo de una constricción cultural más amplia que se ubicaría fácilmente en el marco generalizado de la dominación masculina de que habla Bourdieu (1990). Si ello es así, el resultado neto es que la actuación sexual física resulta negada o minimizada en la respuesta femenina de la encuesta y maximizada en la respuesta masculina. Sería, sin embargo, una explicación demasiado fácil.

Para aprovechar este insight y trabajarlo críticamente utilizaremos como apoyo la conceptuación y terminología del libretismo sexual (scripting) en sus tres planos coordinados, el libreto cultural como normatividad contextual que establece el horizonte en que se desenvuelven los encuentros sexuales, el libreto intrapsíquico que es la expresión individual del deseo y el sentimiento, y el libreto interpersonal que conjuga, mediante una negociación cultural y socialmente constreñida, las reglas del juego sexual $a ̀$ deux. No es el momento de hacer una descripción amplia de esta teoría, basta traer una cita sobre la dificultad existencial que encuentra alguien que desea actuar por sí mismo y se ve constreñido a ajustarse a los dictámenes de los libretos impuestos por la cultura o por la situación (estructuración) social:

El libretismo (scripting) intrapsíquico es aquella actividad mental que es requerida cuando ser un adecuado actor social o modificar determinados materiales de los escenarios culturales resulta muy dificil. Es claro que la relación entre escenarios culturales, libretos interpersonales y libretos intrapsíquicos es compleja y difiere no sólo por medio de las culturas, subculturas y eras, sino entre subgrupos dentro de las culturas y a través de los individuos dentro de las culturas y subculturas. Algunos individuos reproducen fielmente en su conducta cotidiana las instrucciones de los escenarios culturales, sin malestar y a veces con entusiasmo. Otros encuentran alienantes y perturbadoras las demandas de la cultura y se vuelven incapaces de ejercer los roles requeridos o crear modos de aislarse de las demandas de la cultura o de los roles. En estos casos la respuesta puede ser el crimen, la locura, el arte, o la ciencia (Gagnon, 1991: 11).

En el caso de Colombia, y posiblemente de muchos países de Occidente (Flandrin, 1984), el crimen, la locura, el arte o la ciencia no han sido las únicas salidas, pues se ha creado un mecanismo de puerta trasera para la legitimación subrepticia, no reconocida en el discurso, de conductas oficialmente desviadas. Se denomina la doble moral. Ella está abiertamente institucionalizada en nuestro medio para los hombres, aunque -como se verá- no es del todo inexistente para las mujeres. Al repasar someramente la historia del país colombiano-como la de otros países latinoamericanos (Ortega, 1986)- se encuen tra 
efectivamente una proliferación por demás interesante de crímenes, locuras, pecados, e ilegalidades de toda magnitud y condición (véase por ejemplo, Rodríguez, 1991) que emulan con relatos, subrepticios pero también discernibles, de actuaciones culturalmemente normales pero que ocurrían tras el telón de fondo.

La narrativa colombiana de fines del siglo pasado, referente a las mujeres, hizo eco en un tiempo a ciertas "convulsiones" femeninas que tendían a predominar en las jóvenes solteras de clase alta, bajando de frecuencia a medida que se descendía en la escala de las castas sociorraciales y que tenían -para preocupación de las madres- la característica de que la convulsión terminaba indefectiblemente cayendo la enferma en brazos de un visitante (Peralta, 1991: 118). Y la literatura histórica especializada escrita por mujeres (Bermúdez, 1992 y 1994) empieza a reconstruir las imágenes femeninas impuestas por la hegemonía cultural europeizante: las mujeres blancas, europeas y criollas eran vistas como destinadas a casarse, tener hijos o ir al convento, pues se les presionaba para tener una vida casi "asexuada" y "frígida"; por el contrario a las de las "castas" (clases inferiores) se les veía más aptas para la vida sexual por su debilidad innata frente al pecado (Peralta, 1991: 118-126).

Seria interesante recoger lo que se sabe sobre la evolución de la diferenciación en Colombia entre las prudes que dicen siempre no y las coquettes que dicen siempre sí (Luhmann, 1988: 55, 137) y reflexionar sobre la relación de esta bifurcación de la imagen social femenina con la impuesta por la otra idea de que en las clases populares la sexualidad femenina era más actuante y libre para el acceso de los hombres. Vale decir que aun en las clases altas ciertos periodos de turbulencia, como los de las guerras de la independencia, dieron oportunidad para que las mujeres "bien" se liberaran de la normatividad cultural a tal punto que algunas "hicieron girar su vida alrededor de los placeres carnales". Esta permisividad se hizo más patente en la clase media (Peralta, 1991: 118-126).

Sea como fuere, la actuación masculina tras el telón de las formalidades se consideró calladamente aceptable, y hasta expresable en el discurso, cuando los señores o señoritos cruzaban hacia abajo las barreras sociorraciales, pues allí había otro ethos imperante: las concubinas y queridas, aparte de las prostitutas, formaban y forman parte definitiva e importante de la organización social de la sexualidad en Colombia (Gutiérrez de Pineda, 1975). Por otro lado, la violación de niñas e incluso el incesto, que implican una participación forzada por parte de las mujeres, es algo que se calla, pero existe, y en dimensio- 
nes que observadoresijuiciosos consideran muy preocupantes (Gutiérrez de Pineda, 1991). Es una de las formas oscuras, aberrantes y cuasi-normalizadas, en que se manifiesta la violencia en el país.

La alta asociación de la violencia con el ejercicio de la sexualidad adulta, con las mujeres como víctimas, en Colombia ha sido ya documentada por encuestas recientes (Profamilia e IRD 1990: 165-179) a tal punto que no está fuera de tono pensar que la endogeneización de la violencia como rasgo cultural, hoy tan preocupante en el país, tiene mucho que ver con la organización social de la sexualidad colombiana, con los cambios en las reglas de las relaciones íntimas y no íntimas, entre hombres y mujeres (Gutiérrez de Pineda y Vila de Pineda, 1988) y con la inadecuación masculina a estas nuevas exigencias. ${ }^{14}$

La relación de la violencia que caracteriza a Colombia en todos sus ámbitos (Comisión de Estudios sobre la Violencia, 1985) y que ha generalizado una imagen mundial de país violento, con la organización social del erotismo, tal como comienza a bosquejarse en las anteriores descripciones, merece muchísima atención puesto que de pronto allí encontraríamos las raíces para una explicación tanto del dimorfismo que comentamos como de la violencia misma. Se trataría de seguir una estrategia que desmonta muchos sesgos que se han fortalecido a lo largo de más de cuatro décadas de estudios sociológicos sobre la violencia en Colombia (Sevilla, 1991). Aquí damos tan sólo una tímida puntada en tan promisoria dirección explicativa.

Yendo a las raíces de la cultura colombiana, Milagros Palma explora sistemáticamente los mitos y leyendas de indios y mestizos colombianos para sustentar su tesis de que aquí "la mujer es puro cuento", es decir una construcción del hombre para el hombre, y en ella la sexualidad se ha convertido en el punto focal de la dominación en que la mujer es al parecer sólo víctima:

$\mathrm{El}$ abuso sexual es parte del autoritarismo masculino sustentado por los fantasmas alimentados y sostenidos por mitologías y religiones, y ampliamente explotados por las ciencias humanas de la psicología de las profundidades, que postulan un deseo de violación propio del inconsciente

${ }^{14}$ Dice Giddens en un estudio reciente (1992: 122): "En otras palabras, buena parte de la violencia sexual masculina se deriva ahora de la inseguridad e inadecuación más que de una inconsútil continuación de la dominación masculina. La violencia es una reacción destructiva al desvanecimiento de la complicidad femenina". Véase Wade (1994) para una descripción de la asociación violencia-sexualidad-género en la costa atlántica de Colombia. 
femenino. Estudios recientes muestran cómo los hombres han elaborado ese discurso para legitimar su violencia y actuar en la más grande impunidad. El fantasma de la violación que se atribuye a las mujeres como parte constitutiva de la feminidad es puro invento social, un fantasma de los hombres (Palma, 1991: 156).

\section{En busca de explicaciones: una geografia moral hecha de regiones}

Nos permitimos sugerir que las anteriores hipótesis sobre el perfil del erotismo nacional, que se ubican fácilmente bajo la amplia sombrilla de la teoría de la dominación masculina propuesta por Bourdieu (1990), adquieren mejor sentido si se miran atendiendo al mosaico subregional y subcultural colombiano. Éste puede tal vez ayudar a refinar el análisis del discurso y de la representación y evitar fáciles explicaciones sobre perfiles nacionales, que por fuerza hoy se basan en colecciones incompletas de mitos (como lo hace M. Palma) o en comportamientos de variables de encuesta (como lo hacemos aquí a pesar nuestro). No olvidemos que tanto Bourdieu en su ya clásico artículo, como Giddens (véase nota 13) hablan de la complicidad femenina así sea por simple procuración. Sin duda este tipo de complicidad no sale fácilmente a flote en situaciones de habla tipo encuesta y bien podrían buscarse sus trazas en los mitos. Más aún, el desbalance estructural in tergénero puede ser iluminado por lo que ocurre con los desbalances sociorraciales, socioespaciales, e interclases.

El país colombiano se constituyó a partir de aportes raciales y culturales amerindios, europeos y africanos. En un proceso muy complejo y fuertemente ligado a la conformación física del territorio, el orden sociorracial colombiano se regionalizó adquiriendo, hacia inicios del siglo xx, grosso modo la siguiente distribución: el corredor del Pacífico y algunos espacios de los valles cálidos interandinos se mantuvieron como enclaves negros; la región andina de vertiente emergió como blanca-mestiza con frecuentes mezclas de indio-blanco; la llanura del Caribe se desarrolló con una mezcla triétnica con fuerte herencia in dia y negra en las clases bajas y uno que otro enclave más puro de indios o de negros; y la región amazónico-orinoquense permaneció como predominantemente india (Jaramillo Uribe, 1994).

En épocas recientes la colonización de las áreas marginales, sobre todo en el Pacífico y el Oriente, introdujo fuertes componentes mestizos. Igualmente, los muy notables procesos de migración rural-urbana crearon nuevos espacios de relaciones interétnicas e interraciales que plantearon la cuestión en dimensiones totalmente diferentes que 
sin duda marcarán la pauta del futuro. En estos nuevos espacios se favoreció la homogeneización cultural de corte cosmopolita pero también se fortalecieron núcleos microgeográficos en que se refugiaron y siguen refugiándose las etnias regionales. Es el caso, por ejemplo, de los negros migrantes del Pacífico instalados en áreas subnormales de la ciudad de Cali (Urrea y Vanin, 1995) o de indígenas migrantes a ciudades del suroccidente colombiano (Urrea, 1995a).

Estos procesos de espacialización de la demografia nacional están fuertemente ligados a los procesos sociales de jerarquización y discriminación y a los procesos de asunción, exportación, y defensa de patrones culturales de conducta, porque raza, clase social, y género son finalmente construcciones históricas que necesitan expresarse espacialmente. La hipótesis más común es que la sociedad colombiana se organiza.jerárquicamente como en un triángulo en cuyo vértice están los blancos y en la base los indios y los negros. En la ideología nacional el proceso ascendente de blanqueamiento significa ascenso social y mejoramiento del prototipo colombiano (Wade, 1993: 29-47).

Pero, por otro lado, la fuerte regionalización y localización de ciertos conjuntos humanos étnicamente homogéneos, sobre todo de negros e indios, favorece una tendencia contraria a la homogeneización nacional, pues la discriminación social es contrarrestada con fuertes reclamos de originalidad y peculiaridad cultural. Así, pues, es posible encon trar enclaves culturales negros e indios que, aunque no pueden pretender buscar raíces puras no-hispánicas debido al muy fuerte impacto de la colonización y dominación, sí ofrecen alternativas culturales perfectamente discernibles (Wade, 1994: 51-65).

Más aún, Taussig (1987) sugiere que en el encuentro blanco-no blanco (indio/negro) en Colombia se construye una topografía moral, una geografia del sentido, en la cual la segregación y dominación político-económica de los blancos es contrarrestada por los poderes culturales propios -e inalienables-de los dominados (los wild men). Los indios son vistos, por los blancos y por los indios que miran a los blancos mirar a los indios, como dueños de poderes de brujería, magia y curación. Sus chamanes curan los terrores del hombre blanco porque éste los tiene y sólo el indio los puede curar.

Con los negros ocurre un proceso similar: ellos aparecen en el imaginario blanco como dueños de poderes especiales en el campo mágico, sexual, musical y de la danza en un:juego de espejos que reflejan espejos y dejan amplio margen para la ambivalencia, y manipulación, de las relaciones sociorraciales. En el área sexual -fuertemente 
asociada a la expresión musical y de la danza- la población "pura" de los negros ejerce particular fascinación, tematizando la disponibilidad y ardor de la mujer y la virilidad del hombre, asunto tratado de manera mucho más general por Bastide (1961) en relación con los antecedentes históricos de la esclavitud y, recientemente, por Toni Morrison (1992) con referencia al complejo, constitutivo pero silenciado, aporte africanist a la literatura dominante y racista (white) de Estados Unidos. En este juego de espejos se ha construido y sigue construyéndose la complicidad, al menos por procuración, a que nos estamos refiriendo. El ascenso de las revindicaciones étnicas (y feministas) aporta nuevos y muy interesantes elementos para el análisis de esta complicidad.

Entre los indios las reivindicaciones y autoadscripciones étnicas contemporáneas tuvieron inicio en la década de los setenta y recibieron un impulso decisivo con la promulgación de la Constitución Política de 1991. Estos movimientos, hoy extendidos a las comunidades negras a raíz de la aprobación de la Ley 70 sobre comunidades negras, refuerzan el proceso diferenciador advertido por los investigadores desde antes de los movimientos étnicos. El refuerzo viene principalmente por el lado político-económico, pues la Constitución y la ley reconocen formalmente la existencia de entidades territoriales indígenas y de derechos adquiridos por las comunidades negras en determinadas áreas geográficas. Pero el reconocimiento constitucional del territorio, concebido por los grupos étnicos mejor consolidados como entidad física y simbólica, lleva a plantear - de nuevo y con alta pertinencia para los patrones de sexualidad- la cuestión de la revitalización de muchos rasgos culturales y subculturales maltrechos por la homogeneización del "blanqueamiento" mestizo y por la reflexividad ambivalente de las imágenes del yo y del alter Es posible que en el nuevo contex to político las ideas de Taussig sobre la topografía moral y las imágenes interculturales deban ser reformuladas o, por lo menos, actualizadas.

\section{En busca de explicaciones: la europeización a medias de los patrones sexuales}

Aquí entra a:jugar la teoría de los patrones de sexualidad "euroasiático" y "africano", hoy debatida por africanistas y demógrafos (Caldwell, Caldwell y Quiggin, 1989; Orubuloye, 1994). Brevemente, se dice que 
el sistema euroasiático abstrajo de un ordenamiento adquisitivo orientado a asegurar la herencia de propiedades raíces una filosofia sexual de control sobre las mujeres que determina notoriamente el estilo de vida de mucha gente en el mundo lo mismo que las apreciaciones académicas sobre el tema, incluyendo en ellas las estigmatizaciones moralizantes. Dentro de este sistema el control de la sexualidad femenina se constituyó en asunto importante, que a veces fue el eje de todo el sistema moral. Esta filosofia sexual se volvió hegemónica en una muy amplia área geográfica que va desde el Mediterráneo hasta el Ganges y luego se extendió a China. La posterior expansión de las religiones universalistas cristianas e islámicas reforzó el proceso. América no se vio exenta de esta expansión colonizadora.

En cambio, según los autores, África al sur del Sahara se vio libre de esta influencia y mantuvo la actitud descomplicada y pragmática sobre el disfrute de los placeres del amor que las últimas generaciones de Occidente, en su tarea de desinhibición, han tratado de recuperar: no es coincidencia -dicen- el parecido de las estadísticas sobre la conducta sexual tradicional de los adolescentes africanos y la de los adolescentes estadunidenses contemporáneos. La clave de la actitud africana (no de la estadunidense, desde luego) es que los valores religiosos están asociados con la fertilidad y no con la actividad sexual como tal, a tal punto que la abstinencia sexual no es considerada una virtud. El pragmatismo y descomplicación sobre los placeres del amor no se diferencian de mucho de lo hallado respecto a los placeres de la comida y la bebida.

No hay duda de que en Colombia la influencia de la europeización cultural, fortísimamente asociada a la evangelización católica, a pesar de los siglos que lleva, ha dejado intactas -aunque a veces escondidas y liberadas a sus propios desarrollos de enclave- ciertas estructuras valorativas y organizativas en las sociedades de ancestros indios y africanos (éstos, desde luego, definitivamente afectados por la experiencia de la esclavitud). Es posible que la posición relativa en el triángulo sociorracial arriba aludido pueda estar correlacionada con la homogenización cultural europeizante y con estos desarrollos alternativos. La hipótesis de la topografía moral podría refinarse apelando a este esquema triangular.

En efecto, incluso sociedades indígenas sobre las que se han ejercido seculares y sistemáticas presiones evangelizadoras hasta el día de hoy, como las de los Páez, permiten concluir a los investigadores (Bernal, 1955) que su vida religiosa y moral se desdobla en manifesta- 
ciones oficiales europeizantes de carácter público, como las procesiones y las misas, y manifestaciones autóctonas reservadas, particularmente de tipo familiar, que remiten a tradiciones heterodoxas. Curiosamente, en las fiestas "de ellos" que ocurren después de, y al margen de las solemnidades presididas por el cura, se da salida, por medio del chiste y de la acción desinhibida, al disfrute de la sexualidad.

No se ha estudiado de manera sistemática la existencia de rasgos "africanistas" (en el sentido arriba expresado) e indígenas en la sexualidad de los colombianos. Lo que sí es cierto es que se han encontrado marcadas diferencias subregionales en cuanto a la organización familiar y de la sexualidad a ella asociada, y esta subregionalidad está fuertemente correlacionada con la conformación sociorracial del país colombiano. El clásico mapa cultural producido por Virginia Gutiérrez de Pineda (1975) puede leerse como una primera aproximación, indirecta desde luego por su explícito acento en la estructuración familiar, a la regionalización de los patrones sexuales colombianos.

En tal caracterización las denominadas sociedades fluvio-mineras, de ancestro africano, son descritas con rasgos que no están muy distantes -si se suprime la valoración etnocentrista de los relatos- de lo que hoy se narra sobre la sexualidad al sur del Sahara. Por otro lado algunos investigadores colombianos comienzan a revaluar ciertas apreciaciones etnográficas previas sobre la organización familiar en las comunidades negras del Pacífico, que se habían hecho desde un punto de vista centrado en la normatividad de la familia nuclear y en la preeminencia del varón. Según ellos, la poliandria, y la posición especial y fuerte de la mujer en tal tipo de organización, parecen ser más extendidas de lo que antes se había pensado y la actuación sexual femenina muchísimo menos problematizada que lo que permite anticipar el perfil nacional que estamos analizando (Atencio, 1984; Urrea, 1995b).

Desde luego, trabajar con estas nociones puede resultar peligroso. La connotación moralizante y etnocéntrica de la hipótesis sobre el "modelo africano" de sexualidad es difícil de desmontar y su efecto corrosivo para un equilibrado estudio comparativo fue advertido por sus mismos proponentes: cualquier patrón diferente que no se ajuste a la moralidad dominante, sobre todo si pertenece a categorías sociales subordinadas, es rápidamente estigmatizado y condenado. Más aún, como lo sugiere Morrison (1992: 80), cualquier expresión modificadora de la moralidad sexual imperante, si es realizada por los superordinados es tratada por los dueños de la palabra, como generative 
sexuality mientras que si es realizada por los subordinados e inferiores es condenada como outlaw sexuality.

Epílogo: cómo se aman o cómo se matan

Ante esta perspectiva de importantes variaciones subculturales y regionales la imagen de un perfil nacional contradictorio, por su diferenciación hombre-mujer, se relativiza y reclama urgentes reconsideraciones. Desafortunadamente los materiales etnográficos disponibles no permiten trabajar con rigor estas variaciones subregionales y dentro de ellas las sutiles formas de complicidad femenina que, fuera de toda duda, han existido. Es decir, la cuestión queda apenas planteada. En concreto, queda como campo abierto a la investigación qué tienen que decir los negros, los indios, los mestizos y los blancos, tan to hombres como mujeres sobre su sexualidad, y cuáles son las conductas que corresponden localmente a las evocaciones de vivencias y reflexiones post hoc que logren suscitarse en la investigación etnográfica. Igualmente, queda abierta la pregunta sobre los arquetipos míticos de la población afrocolombiana que sin duda podría modificar las generalizaciones que sobre Colombia hace Palma (1991), pues precisamente esta importante alternativa cultural colombiana en que la mujer parece tener un papel tan importante en la estructuración de la vida íntima, no aparece representada en el corpus de la autora.

Se deja por tanto planteado el muy interesante tema de la variación subnacional (regional o subcultural) que, de acuerdo con la teoría del scripting, posiblemente arraje mucha más luz sobre esta área de la acción social que los perfiles nacionales. En efecto, al postular que la sexualidad no es un datum o fatum transculturalmente uniforme, sino una construcción contingente, de fuerte coloración localista, que se ingenian los humanos (hombres y mujeres) para definir y dar satisfacción a sus urgencias placenteras y amorosas, nos estamos remitiendo a las raíces familiares, locales y regionales que dan expresión sui generis a la normatividad general que ha tratado de homogeneizar conjuntos nacionales.

De todos modos, el estudiar y comparar los perfiles nacionales constituye un buen punto de partida. Insistimos, es apenas un buen punto de partida para iniciar el proceso de saber sociológicamente por otros medios cómo es la sociedad colombiana, teniendo como 
punto de mira la muy pertinente pregunta sobre cómo se aman. Esto sería una interesante alternativa a la ya voluminosa literatura que responde a la pregunta sobre cómo se matan. Particular importancia parece tener la necesaria complicidad femenina, al menos por procuración. Ella ha debido darse, como bien lo recuerda Bourdieu, aun para que una muy fuerte y generalizada dominación masculina haya sido establecida. La descripción crítica de esta participación femenina sería tanto más iluminadora como difícil parece ser sacarla al plano discursivo por los medios usuales de la investigación sociológica.

\section{Bibliografía}

Alberoni, Francesco (1988), El eratismo, Barcelona, Gedisa.

Augé, Marc (1993), Le sens des autres: actualité de l'anthropologie, París, Fayard.

Badinter, Elizabeth (1993), XY. La identidad masculina, Santa Fe de Bogotá, Norma.

Bajos, Nathalie y Alfred Spira (1993), "L'enquête ACSF: élaboration d'un projet multidisciplinaire sur la sexualité", Population, núm. 5, pp. 12091228.

Bastide, Roger (1961), "Dusky Venus, Black Apollo", Race, núm. 3, pp. 10-19.

Bataille, Georges (1988), El erotismo, Barcelona, Tusquets.

Bateson, George (1993), "Sexo y cultura", Una unidad sagrada: pasos ulteriores hacia una ecologia de la mente, Madrid, Gedisa, pp. 70-87 [1946].

Bermúdez, Susy (1992), Hijas, esposas y amantes: ensayos sobre el género, clase y etnia en la historia de Latinoamérica, Bogotá, Universidad de los Andes.

(1994), El bello sexo durante el siglo XIx en Colombia, Bogotá, Universidad de los Andes.

Bernai, Segundo (1956), "Religious life of the Paez Indians of Colombia", tesis de maestria en antropología, Nueva York, Columbia University.

Bozon, Michel (1993), "L'entrée dans la sexualité adulte: le premier rapport et ses suites, du calendrier aux attitudes", Population, vol. 48, núm. 5, pp. 1317-1352.

- y H. Leridon (coords.) (1993), "Sexualité et sciences sociales: les apports d'une enquête", Population, vol. 48, núm. 5, pp. 1173-1550.

Bourdieu, Pierre (1990), "La domination masculine", Actes de la Recherche en Sciences Sociales, núm. 2 (número especial sobre la mujer).

Caplan, Pat (1987), "Introduction", en P. Caplan (ed.), The Cultural Construction of Sexuality, Londres, Routledge, pp. 1-30.

Cicourel, Aaron V. (1964), Method and Measurement in Sociology, Nueva York, The Free Press. 
Comisión de Estudios sobre la Violencia (1985), "Colombia: violencia y democracia", informe presentado al Ministerio de Gobierno, Bogotá, Universidad Nacional de Colombia y Colciencias.

Eco, Umberto (1989), "Cuernos, cascos, zapatos: algunas hipótesis sobre tres tipos de abducción", en Holme Peirce Dupin, U. Eco y T. Sebeok (eds.), El signo de los tres, Barcelona, Lumen, pp. 265-294.

Flandrin, Jean-Louis (1984), "La moral sexual en Occidente. Evolución de las actitudes y comportamientos", Barcelona, Granica.

Foucault, Michel (1976), Histoire de la Sexualité, t. 1: La volonté de savoir, Paris, Gallimard.

(1984), Histoire de la Sexualité, t. 2: L'usage des plaisirs, París, Gallimard. - (1990), Tecnologías del yo y otros textos afines, Barcelona, Paidós Ibérica.

Gagnon, John (1991), "The Implicit and Explicit Use of Scripts in Sex Rese; arch", en John Bancroft, Clive Davis y Deborah Weinstein (eds.), The Annual Review of Sex Research, t. 1, Mt. Vernon, Iowa, Society for the Scientific Study of Sex, pp. 1-41.

Giddens, Anthony (1992), The Transformation of Intimacy: Sexuality, Love and Eroticism in Modern Societies, Stanford, Stanford University Press.

Gutiérrez de Pineda, Virginia (1975), Familia y cultura en Colombia, Bogotá, Colcultura (Biblioteca Básica Colombiana, 3).

__ (1991), "Poder y violencia en la familia patriarcal", Colombia Médica, núm. 22S, pp. 21-27.

- y Patricia Vila de Pineda (1988), Honor, familia y sociedad en la estructura patriarcal: el caso de Santander, Bogotá, Universidad Nacional de Colombia.

Habermas, Jürgen (1987), Teoría de la acción comunicativa, vol. 1, Madrid, Altea/Taurus/Alfaguara.

Iss (Instituto de Seguros Sociales y Profamilia) (1993), Encuesta sobre conocimientos, actitudes y prácticas relacionadas con enfermedades de transmisión sexual, sida, enfermedades cardiovasculares, cáncer y accidentes, tomo Y: Características de la población y de la muestra, Santa Fe de Bogotá.

Jaramillo Uribe, Jaime (1994), La personalidad histórica de Colombia y otros ensayos, Bogotá, El Áncora.

Kofes, Swely (1992), "Experiencias sociais, interpretacióes individuais: históricas de vida, sus possibilidades e límites", trabajo presentado en el Seminario Internacional de Uso de Historias de Vida en Ciencias Sociales: Prácticas, Teorías y Metodologías, Villa de Leyva, 17-22 de marzo.

Laumann, O., J. H. Gagnon, R. T. Michael, y S. Michaels (1994), The Social Organization of Sexuality: Sexual Practices in the United States, Chicago, The University of Chicago Press.

Luhmann, Niklas (1985), El amor como pasión, Barcelona, Ediciones Península.

Le Goff, Jacques (1991), El orden de la memoria: el tiempo como imaginario, Barcelona, Paidós. 
Lipoweski, Gilles (1993), L'ére du vide: essais sur l'individualisme contemporain, París, Gallimard.

May R. M., R. M. Anderson y S. M. Blower (1989), "The Epidemiology and Transmission of hiv-AIns", Daedalus, vol. 118, núm. 2. pp. 163-201.

Merson, Michael H. (1993), "Slowing the Spread of HIv: Agenda for the 1990's", Science, núm. 260, pp. 1266-1268.

Morrison, Toni (1992), "Playing in the Dark: Whiteness and the Literary Imagination", Nueva York, Random House.

ops (Organización Panamericana de la Salud) (1993), "Manual de encuestas sobre conocimientos, actitudes, creencias y prácticas (CACP) sobre sida y ETS", versión preliminar, Washington $D$. C.

Ortega, S. (ed.) (1986), De la santidad a la perversión: o de por quẻ no se cumplía la ley de Dios en la sociedad novohispana, México, Grijalbo.

Orubuloye, I. O. (ed.) (1994), Sexual Networking and ADs y Sub-Saharan Africa: Behavioural Research and the Social Context, Camberra, Health Transition Centre, The Australian National University.

Palma, Milagros (1991), La mujer es puro cuento: feminidad aborigen y mestiza, Santa Fe de Bogotá, Tercer Mundo Editores.

Parker, R. G., G. Herdt y M. Carballo (1991), "Sexual Culture, HIv Transmission, and AIDs Research", en Joumal of Sex Research, vol. 28, núm. 1, pp. 77-98.

Paz, Octavio (1993), La llama doble: amor y erotismo, Barcelona, Seix Barral.

Peralta, Victoria (1991), El ritmo lúdico y los placeres en Bogotá, Santa Fe de Bogotá, Planeta Editorial Colombiana.

Profamilia e Institute for Resource Development (1990), Encuesta de Prevalencia, Demografia y Salud 1990, Santa Fe de Bogotá.

Rodríguez, Pablo (1991), Seducción, amancebamiento y abandono en la Colonia, Bogotá, Fundación Simón y Lola Guberek (Colección Historia, 2).

Schlieben-Lange, Brigitte (1988), Pragmática lingüística, Madrid, Gredos.

Seidler, Victor J. (1987), "Reason, Desire, and Male Sexuality", en P. Caplan (ed.), The Cultural Construction of Sexuality, Londres, Routledge, pp. 82112.

Sennet, Richard y Michel Foucault (1981), "Sexualidad y soledad", El Viejo Topo, núm. 61, pp. 47-54.

(1995), "To the Editor", The New York Review of Books, vol. 42, núm. 9, p. 43.

Sevilla, Elias (1991), "Hacia una epidemiología de la violencia: el caso de Colombia”, Colombia Médica, núm. 22S, pp. 3-11.

(1995), "Prosa antropológica sobre sexualidad, erotismo y amor", en E. Sevilla (ed.), Prosa antropológica y otros ensayos sobre sexualidad, erotismo y amor, Cali, Universidad del Valle/cibse (Documentos de Trabajo, 23), pp. 15-52.

, Katia Feliciano y Javier Olaya (1995), Dueños de si.y de sus deseos: estudio sobre la sexualidad de los colombianos y su vulnerabilidad al viH, Cali, Facultad de Ciencias Sociales y Económicas, Universidad del Valle. 
Simmel, Georg (1971), "Eros, Platonic and Modern", en D. A. Levine (ed.), Georg: Simmel on Individuality and Social Forms, Chicago, The University of Chicago Press, pp. 235-248.

Stone, Lawrence (1995), "What, How Often and With Whom?", London Review Books, vol. 17, núm. 5.

Taussig, Michael (1987), Shamanism, Colonialism, and the Wild Man: A Study in Terror and Healing, Chicago, The University of Chicago Press.

Urrea, Fernando (1995a), "Pobladores urbanos redescubiertos: presencia indígena en ciudades colombianas", trabajo presentado en el Seminario Internacional Investigación Sociodemográfica Contemporánea de Pueblos Indígenas, Santa Cruz, Bolivia, 18-22 de octubre.

(1995b), Proyecto "Organización Social, Dinámicas Culturales e Identidades de las Poblaciones Afrocolombianas del Pacífico y Suroccidente en un Contexto de Movilidad y Urbanización", Cali, Universidad del Valle/cDSE.

y Alfredo Vanin (1995), "Religiosidad popular no oficial alrededor de la cultura del tabaco, instituciones sociales y procesos de modernidad en poblaciones negras de la costa pacífica colombiana", Boletin Socioeconómico, cIDsE, núm. 28, pp. 35-58.

Wade, Peter (1993), Blackness and Race Mixture: The Dynamics of Racial Identity in Colombia, Baltimore, The Johns Hopkins University Press.

(1994), "Man the Hunter: Gender and Violence in Music and Drinking Contexts in Colombia", en P. Harvey y P. Gow (eds.), Sex and Violence: Issues in Representation and Experience, Londres, Routledge, pp. 115-137.

Weeks, Jeffrey (1987), "Questions of Identity", en P. Caplan (ed.), The Cultural Construction of Sexuality, Londres, Routledge, pp. 31-51.

who (World Health Organization) (1988), "World Summit of Ministers of Health on Programmes for AIDs Prevention, London 26-28, January 1988", Ginebra, Global Programme on AIDs (Progress Report, 4). 